\title{
A Model of Anomaly Discovery
}

Liu, Qi, Lei Lu, Bo Sun, and Hongjun Yanand
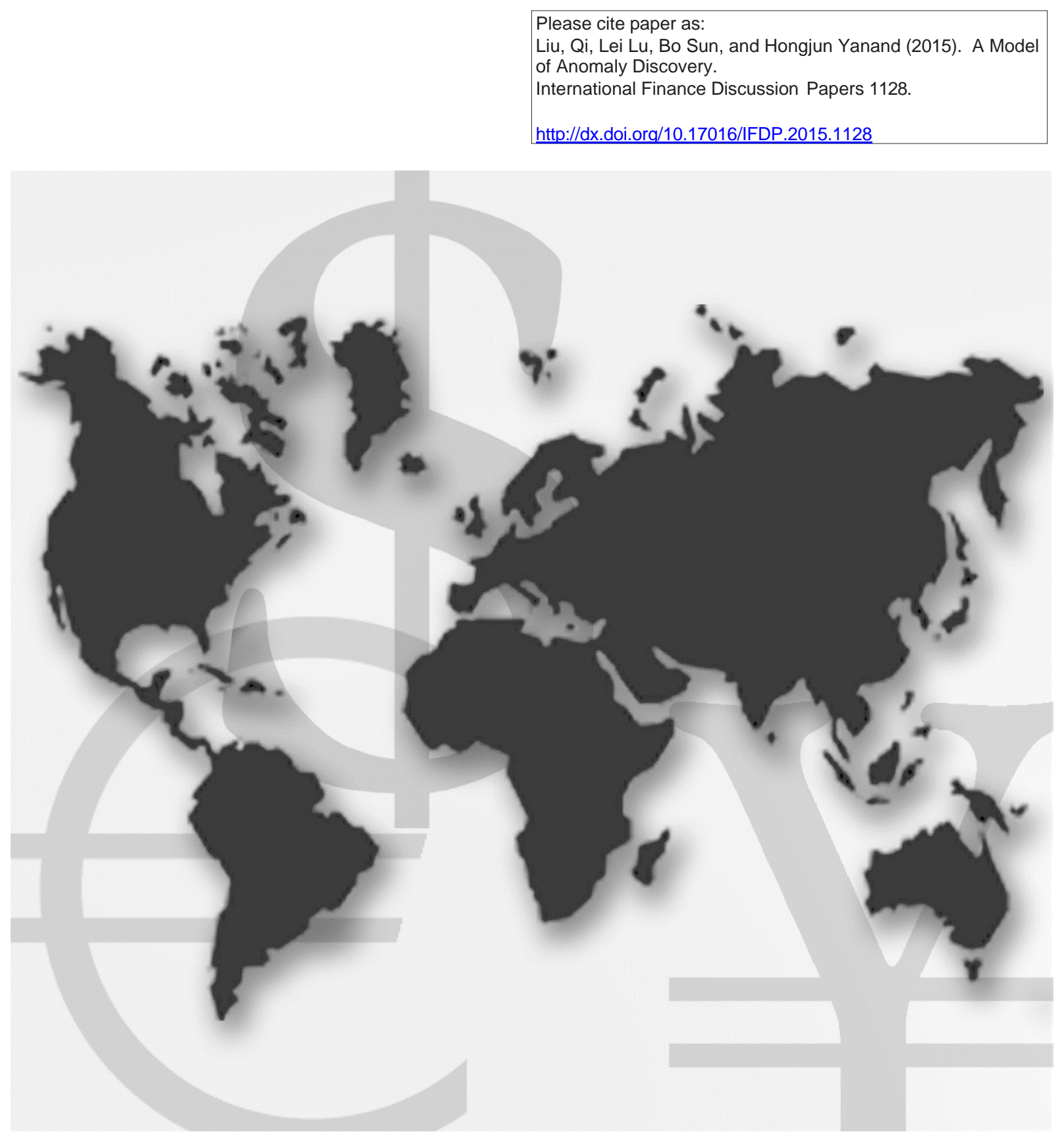

\section{International Finance Discussion Papers}

Board of Governors of the Federal Reserve System

Number 1128

January 2015 


\section{Board of Governors of the Federal Reserve System \\ International Finance Discussion Papers}

Number 1128

January 2015

\section{A Model of Anomaly Discovery}

Qi Liu, Lei Lu, Bo Sun, and Hongjun Yan

NOTE: International Finance Discussion Papers are preliminary materials circulated to stimulate discussion and critical comment. References to International Finance Discussion Papers (other than an acknowledgment that the writer has had access to unpublished material) should be cleared with the author or authors. Recent IFDPs are available on the Web at www.federalreserve.gov/pubs/ifdp/. This paper can be downloaded without charge from the Social Science Research Network electronic library at www.ssrn.com. 


\title{
A Model of Anomaly Discovery
}

\author{
Qi Liu, Lei Lu, Bo Sun, and Hongjun Yan
}

\begin{abstract}
:
We analyze a model of anomaly discovery. Consistent with existing evidence, we show that the discovery of an anomaly reduces its magnitude and increases its correlation with existing anomalies. One new prediction is that the discovery of an anomaly reduces the correlation between deciles 1 and 10 for that anomaly. Using data for 12 well-known anomalies, we find strong evidence consistent with this prediction. Moreover, the correlation between deciles 1 and 10 of an anomaly becomes correlated with the aggregate hedge-fund wealth volatility after the anomaly is discovered. Our model also sheds light on how to distinguish between risk- and mispricing-based anomalies.
\end{abstract}

Keywords: Anomaly, Arbitrage, Discovery, Arbitrageur-based asset pricing.

JEL classifications: G11, G23

One of the authors is a staff economist in the Division of International Finance, Board of Governors of the Federal Reserve System, Washington, D.C. 20551 U.S.A. The views in this paper are solely the responsibility of the authors and should not be interpreted as reflecting the views of the Board of Governors of the Federal Reserve System or of any other person associated with the Federal Reserve System. 


\title{
A Model of Anomaly Discovery
}

\begin{abstract}
We analyze a model of anomaly discovery. Consistent with existing evidence, we show that the discovery of an anomaly reduces its magnitude and increases its correlation with existing anomalies. One new prediction is that the discovery of an anomaly reduces the correlation between deciles 1 and 10 for that anomaly. Using data for 12 well-known anomalies, we find strong evidence consistent with this prediction. Moreover, the correlation between deciles 1 and 10 of an anomaly becomes correlated with the aggregate hedge-fund wealth volatility after the anomaly is discovered. Our model also sheds light on how to distinguish between risk- and mispricing-based anomalies.
\end{abstract}

Keywords: Anomaly, Arbitrage, Discovery, Arbitrageur-based asset pricing.

JEL Classifications: G11, G23. 


\section{Introduction}

A significant portion of the asset-pricing literature has been devoted to "anomalies," empirical patterns that appear inconsistent with existing benchmark models. One popular approach to interpreting anomalies is risk-based. Take the value premium as an example. Its discovery is often attributed to Basu (1983). Since then, numerous models have been proposed to explain why value stocks are indeed riskier (than what CAPM implies) and so have higher expected returns.

We argue that this approach ignores the discovery aspect. In those risk-based models, investors know that value stocks are riskier and demand higher returns. As expected, higher average returns are realized for value stocks in the data. That is, in this view, there is no real discovery: Professor Basu was the last one in the world to find out about the value premium. Investors knew about this return pattern all along.

In contrast to the view above, it seems natural to expect discoveries to have significant effects on investors' decisions and asset prices since, over the years, discoveries in academia have had increasingly important influences on the asset management industry. Many prominent asset management companies regularly organize academic seminars and conferences. Some explicitly claim that they identify investment ideas from academic research. ${ }^{1}$ In this paper, we explicitly model anomaly discovery and analyze its effects on asset prices, both theoretically and empirically.

We solve a simple model with two assets (asset 1 and asset 2) that have the same distribution for future cash flows. However, investors find asset 1 riskier because their endowment is correlated with asset 1's cash flow, but not with asset 2's. Consequently, in equilibrium, asset 1 has a lower price and a higher expected future return than asset 2. We call this return pattern an "anomaly," which is risk-based since it is caused by investors' risk consideration.

\footnotetext{
${ }^{1}$ Take Dimensional Fund Advisors as an example. According to its website, as of June 30, 2014, it manages $\$ 378$ billion. Academic research appears to have a deep influence on its operation, as its website states: "Working closely with leading financial academics, we identify new ideas that may benefit investors."
} 
When this anomaly is discovered, some agents, who we call "arbitrageurs," become aware of the return pattern and start exploiting it. To analyze the discovery effect, we construct an equilibrium without these arbitrageurs, which we call a "pre-discovery equilibrium," and an equilibrium with these arbitrageurs, which we call a "post-discovery equilibrium." The discovery effect is captured by the difference between the pre- and post-discovery equilibria. ${ }^{2}$

Our model has the following implications. First, the discovery of an anomaly reduces its magnitude. This follows directly once we recognize that the discovery brings in arbitrageurs. Let us use the value premium as an example. It has been proposed that value stocks are riskier because they are more exposed to the business cycle. Arbitrageurs, however, may not find this risky, perhaps because they are wealthy and are themselves less exposed to the business cycle. Hence, they will exploit this anomaly and consequently reduce its magnitude. ${ }^{3}$

Second, the discovery of an anomaly makes its return (i.e., the return from a long position in asset 1 and a short position in asset 2) more correlated with the returns from existing anomalies. This is due to a wealth effect when arbitrageurs exploit both existing anomalies and the newly discovered one. Suppose the return from existing anomalies is unexpectedly high one period, thus increasing arbitrageurs' wealth. Everything else being equal, arbitrageurs will allocate more investment to all their opportunities, including the new anomaly. This higher investment pushes up the price of asset 1 and pushes down the price of asset 2, leading to a high return from the new anomaly this period. Similarly, a low return from existing anomalies leads to a low return from the newly discovered one. Hence, the wealth effect increases the correlation between the new anomaly return and the returns from existing anomalies.

Third, the discovery reduces the correlation between the returns of assets 1 and 2, and this effect is stronger when arbitrageurs' wealth is more volatile. The intuition is as follows. After

\footnotetext{
${ }^{2}$ The traditional approach can be viewed as a special case, in which arbitrageurs' wealth is zero. In this case, the pre- and post-discovery equilibria coincide and the discovery has no effect on asset prices.

${ }^{3}$ For example, in an article written by several senior managers at AQR, Asness, Frazzini, Israel, and Moskowitz (2014) state that "[w]e are fans of both momentum and value..." They also state that "none of this debate [about whether momentum is due to risk or mispricing] should diminish momentum as a valuable investment tool."
} 
the discovery, arbitrageurs have a long-short position in assets 1 and 2, as well as investments in other opportunities. Suppose the arbitrageurs' wealth increases due to, say, a high return from their investments or fund flows from their investors. They will buy asset 1 and sell asset 2. This increases asset 1's return but decreases asset 2's. Similarly, when arbitrageurs' wealth decreases, they will unwind some of their long-short positions, i.e., sell asset 1 and buy asset 2, which decreases asset 1's return but increases asset 2's. In both cases, arbitrageurs' wealth shocks push the returns of the two assets to opposite directions, reducing their correlation. Naturally, this intuition also suggests that the effect is stronger when arbitrageurs' wealth is more volatile.

To contrast with the above risk-based anomaly, we also analyze a version of our model where the anomaly is due to mispricing. Specifically, we modify the previous model so that investors do not have the hedging need in asset 1 , but mistakenly believe that asset 1's future cash flow is lower than asset 2's. Our analysis shows that the discovery of this mispricing-based anomaly has exactly the same three asset-pricing implications as those discussed above. Hence, our analysis suggests that in order to distinguish between risk- and mispricing-based anomalies, it is not promising to focus only on asset prices. What is the solution? One possibility is to examine investors' portfolios instead, because risk- and mispricing-based anomalies have starkly different implications for investors' portfolios. For the value anomaly, for example, one can check if the investors who underweight value stocks appear to be those whose labor income or other assets are indeed more exposed to the risk proposed in the risk-based model. While this approach is demanding on the required dataset, in this big data era, with more and more micro-level datasets becoming available, this approach might not be a fantasy, either.

Both the risk- and mispricing-based versions of our model have the same three main predictions. The first two are consistent with existing empirical evidence. For example, McLean and Pontiff (2013) analyze the post-discovery performance of 82 anomalies, and find that postdiscovery anomaly returns decay by $44 \%$ on average. They also find that after the discovery, the new anomaly return becomes more correlated with the returns from existing anomalies. 
The third prediction is new to the literature, and we empirically test it. According to Harvey, Liu, and Zhu (2014), there are more than 300 anomalies documented in the academic literature. However, one would expect that for a discovery to have a first-order effect on underlying stock prices, the anomaly would need to be widely known and exploited by a large number of arbitrageurs. Hence, we first analyze the three arguably most widely known anomalies - size, value, and momentum - before we expand to a broader set of influential anomalies.

Our goal is to test, for each anomaly, whether the correlation between deciles 1 and 10, formed from the corresponding portfolio sort, decreases after the discovery of the anomaly. For each anomaly, we use a 5-year rolling window to estimate the correlation coefficient between the monthly excess returns of deciles 1 and 10 during 1927-2013. The estimates are plotted in Figure 1. For momentum in Panel A, this correlation fluctuated between 0.6 and 0.8 in the first six decades. In the early 1990s, however, it dropped significantly to around 0.4. This drop coincided with the publication of the most influential study on momentum, Jegadeesh and Titman (1993). We also see similar large drops in this correlation for size and value anomalies in Panels B and C. ${ }^{4}$ Interestingly, although these two anomalies were documented in the early 1980s (Banz (1981) and Basu (1983)), the correlations did not drop sharply until the early 1990s. This coincides with Fama and French's influential work (e.g., Fama and French (1992)) that narrows down a number of anomalies to size and value.

To formally test the changes in the correlation between deciles 1 and 10, we control for its potential time trend by normalizing it with the correlation between deciles 5 and 6 . The idea is that arbitrageurs are likely to take larger long-short positions in deciles 1 and 10 than in deciles 5 and 6 . Hence, the correlation between deciles 5 and 6 should have little or no discovery effect, but should share the common time trend with the correlation between deciles 1 and 10. Hence, in our tests, we use the correlation ratio: the correlation between deciles 1 and 10 divided by the correlation between deciles 5 and 6 .

\footnotetext{
${ }^{4}$ In Panels B and C, the correlations revert back to their pre-discovery level after 2000. We are not sure about the reasons behind the large increase in the correlations for size and value in the last 10 years.
} 
For each anomaly, we regress the correlation ratio on a dummy variable that takes the value of 0 before the chosen "discovery time" of the anomaly and 1 afterwards. For momentum, if we choose the publication time for Jegadeesh and Titman (1993) as the discovery time, the coefficient for the discovery dummy is -0.13 , with a $t$-statistic of -3.97 . This implies that the correlation ratio decreases by 0.13 after the discovery. For size and value anomalies, if we use the publication time of the original studies (Banz (1981) and Basu (1983)) as the discovery time, the coefficient for the discovery dummy is $-0.07(t=-1.15)$ for size and $-0.09(t=-1.78)$ for value. In contrast, if we use the publication time for Fama and French (1992) as the discovery time, the coefficient estimates become more significant both in magnitude and statistically: $-0.14(t=-1.78)$ for size and $-0.13(t=-1.96)$ for value.

Our most compelling evidence is the direct link between the correlation and hedge funds' activity. Our model predicts that the correlation is decreasing in the volatility of arbitrageurs' wealth, which is proxied by the volatility of the aggregate assets under management (AUM) by hedge funds. For each anomaly, we regress its correlation ratio on the estimated hedge fund wealth volatility. Consistent with our model prediction, the coefficient for the wealth volatility is highly significant for all three anomalies: the coefficient estimates are $-6.78(t=-2.23),-37.31$ $(t=-6.25)$, and $-17.62(t=-6.74)$, for momentum, size, and value, respectively.

We expand our analysis to include the list of anomalies that are studied in Stambaugh, Yu, and Yuan (2012). Apart from a robustness check, the broader set of anomalies also offers a stronger test to our model prediction: Our model implies that the post-discovery correlation between deciles 1 and 10 is decreasing in the volatility of arbitrageurs' wealth, but this relation does not hold before discovery. In our previous analysis, we could not contrast the pre- and post-discovery implications, because our hedge fund data start in 1999, long after the discovery of all three anomalies. With the list of 12 anomalies, however, this comparison becomes possible because half of them were discovered after 1999.

Specifically, we run two panel regressions of the correlation ratio for the 12 anomalies on hedge 
funds' wealth volatility. In the first regression, we include the entire available sample during 19992012. Since six anomalies were discovered after 1999, this regression includes their pre-discovery data. In contrast, we exclude those pre-discovery data in the second regression. Our model implies that the coefficient for hedge funds' wealth volatility should be significantly negative in the second regression, but weaker in the first one. This is exactly what we find. The estimate for this coefficient is $-4.18(t=-1.00)$ in the first regression, and $-11.75(t=-2.21)$ in the second one.

Our paper is closely related to the analyses of arbitrageurs' risk-bearing capacity (e.g., Dow and Gorton (1994), Shleifer and Vishny (1997), Xiong (2001), and Kyle and Xiong (2001)). More broadly, our paper belongs to the literature that explores the role of arbitrageurs in asset pricing (e.g., Gromb and Vayanos (2002), Liu and Longstaff (2004), Basak and Croitoru (2006), Brunnermeier and Pedersen (2009), Kondor (2009), He and Krishnamurthy (2013), Kondor and Vayanos (2013), Chinco (2014), Drechsler and Drechsler (2014), and Stambaugh, Yu, and Yuan $(2012,2014))$. These studies focus on the impact of arbitrageurs in contagion, risk sharing, liquidity, portfolio choice, limit of arbitrage, the relation between the cost of shorting and anomaly returns, and so on, while our paper focuses on the effect of discovery. There is an enormous literature on anomalies, exploring explanations that are consumption-based (e.g., Bansal, Dittmar, and Lundblad (2005)), investment-based (e.g., Hou, Xue, Zhang (2014)), institution-based (e.g., Vayanos and Woolley (2013)), and behavioral-based (e.g., Baker and Wurgler (2006)). See Harvey, Liu, and Zhu (2014) for a comprehensive list. While these explanations generally abstract away from the discovery aspect, we take it seriously and formally analyze its consequences. According to Cochrane (1999), the discovery aspect "is (so far) the least stressed in academic analysis. In my opinion, it may end up being the most important."

The rest of the paper is as follows. Sections 2 presents a model of risk-based anomaly, Section 3 analyzes a mispricing-based anomaly, Section 4 tests the main new predictions, and Section 5 concludes. The numerical algorithm and proofs are in the appendix. 


\section{A model of the discovery of a risk-based anomaly}

We consider a two-period model, with time $t=0,1,2$. Trading takes place at $t=0,1$, and consumption occurs at $t=2$. There is one risk-free asset, and its interest rate is normalized to 0 . There are two risky assets, asset 1 and asset 2, each of which is a claim to a single cash flow at $t=2$. There is a continuum of identical investors, with a population size of one. At $t=0$, investors are endowed with one unit of each asset and $k$ dollars cash.

The cash flows from assets 1 and 2 are independent and have the same ex ante distribution. Specifically, for $i=1,2$, and $t=0,1$, we have

$$
D_{i, t+1}=D_{i, t} \times \mu_{i, t+1}
$$

where $D_{i, 0}=1$, and $\mu_{i, t+1}$ are independent across $i$ and $t$, and have the same binary distribution:

$$
\mu_{i, t+1}= \begin{cases}\mu+\sigma & \text { with probability } p \\ \mu-\sigma & \text { with probability } 1-p,\end{cases}
$$

where $\mu>\sigma>0$, and $0<p<1$. Asset $i$ is a claim to a cash flow $D_{i, 2}$ at time $t=2$. Hence, the two cash flows (i.e., $D_{1,2}$ and $D_{2,2}$ ) are independent from each other and have the same distribution at $t=0$.

For $i=1,2$, and $t=0,1,2$, we use $P_{i, t}$ to denote the price of asset $i$ at time $t$, which will be determined endogenously in equilibrium. At $t=2$, asset prices are pinned down by the final cash flow: $P_{i, 2}=D_{i, 2}$. Let us denote the gross return of asset $i$ at time $t$, for $t=1,2$, as

$$
r_{i, t} \equiv \frac{P_{i, t}}{P_{i, t-1}}
$$

\subsection{Risk-based anomaly}

Investors are endowed with a nontradable asset (e.g., labor income), which is a claim to a cash flow $\rho D_{1,2}$ at $t=2$, with $\rho \geq 0$. That is, this endowment is perfectly correlated with the payoff from asset 1. Denote investors' wealth, excluding their nontradable endowment, at time $t$ as $W_{t}$ 
for $t=0,1,2$. If investors allocate a fraction $\theta_{i, t}$ of $W_{t}$ to asset $i$ at time $t$, for $i=1,2$ and $t=0,1$, their wealth dynamic is given by

$$
W_{t+1}=W_{t}\left[\sum_{i \in\{1,2\}} \theta_{i, t} r_{i, t+1}+\left(1-\sum_{i \in\{1,2\}} \theta_{i, t}\right)\right],
$$

with $W_{0}=k+P_{1,0}+P_{2,0}$. Investors' objective is to choose $\theta_{i, t}$, for $i=1,2$, and $t=0,1$, to

$$
\max _{\theta_{i, t}} E_{0}\left[\log \left(W_{2}+\rho D_{1,2}\right)\right]
$$

subject to (3). In reduced form, the above formulation captures the essence of risk-based anomalies: Investors find asset 1 riskier because its return is correlated with their endowment.

\subsection{Anomaly discovery}

Traditional risk-based explanations of anomalies abstract away from the discovery aspect. Let us use the value premium as an example. By definition, the discovery of the value premium in Basu (1983) should make at least some market participants aware of the return pattern for the first time, unless one believes Basu was actually the last person to find out about the return pattern. In traditional risk-based models of the value premium, however, all investors knew about the value premium even before the discovery in Basu (1983). That is, this traditional approach does not take into account the effect of discovery.

We focus on exactly this discovery aspect. That is, the discovery of the anomaly informs some agents about the return pattern for the first time. For convenience, we call those agents "arbitrageurs," to highlight their difference from the previously-described "investors."

There is a continuum of identical arbitrageurs, with a population size of one. Their aggregate wealth at $t=0$ is $W_{0}^{a} \geq 0$ dollars in cash. They have access to another investment opportunity, which presumably exploits existing anomalies (say, e.g., currency carry trade). This opportunity is not available to the investors described earlier, perhaps because those investors do not have the expertise to analyze and implement the strategy. We call this existing anomaly "asset $e$," and 
assume its gross return at $t=1,2$ is

$$
r_{e, t}= \begin{cases}\mu_{e}+\sigma_{e}, & \text { with probability } p_{e}, \\ \mu_{e}-\sigma_{e}, & \text { with probability } 1-p_{e},\end{cases}
$$

where $\mu_{e}>\sigma_{e}>0$, and $0<p_{e}<1$. Moreover, $r_{e, t}$ is assumed to be independent from $D_{i, t}$. That is, the fundamentals of assets 1 and 2 are independent from the existing anomaly —asset $e$.

To analyze the discovery effect, we compare the equilibria in the following two economies. In the first (pre-discovery) economy, arbitrageurs are not aware of the anomaly (i.e., that assets 1 and 2 have the same fundamentals but different prices at $t=0)$. Hence, they invest in asset $e$, but not in assets 1 or 2 . In the second (post-discovery) economy, arbitrageurs become aware of the anomaly and start exploiting it, as well as investing in the existing anomaly - asset $e$. To capture this, we assume that arbitrageurs take a long-short strategy in the two assets so that they can exploit the anomaly and stay "market neutral." ${ }^{5}$ Specifically, we use $\theta_{i, t}^{a}$ to denote the fraction of arbitrageurs' wealth that is invested in asset $i=1,2$, at time $t=0,1$. A market-neutral strategy is such that, for $t=0,1$,

$$
\theta_{1, t}^{a}+\theta_{2, t}^{a}=0
$$

Let us use $\theta_{e, t}^{a}$ to denote the fraction of arbitrageurs' wealth that is invested in asset $e$ at time $t=0,1$. Then, arbitrageurs' wealth dynamic is given by

$$
W_{t+1}^{a}=W_{t}^{a}\left[\sum_{i \in\{1,2, e\}} \theta_{i, t}^{a} r_{i, t+1}+\left(1-\sum_{i \in\{1,2, e\}} \theta_{i, t}^{a}\right)\right],
$$

for $t=0,1$. Their objective is to choose $\theta_{i, t}^{a}$ for $i=1,2, e$, and $t=0,1$, to

$$
\max _{\theta_{i, t}^{a}} E_{0}\left[\log \left(W_{2}^{a}\right)\right]
$$

subject to (5) and (6).

\footnotetext{
${ }^{5}$ This assumption is made so that arbitrageurs focus on exploiting the anomaly. Alternatively, we can simply assume that after the discovery, arbitrageurs become aware of the existence of assets 1 and 2. Under this alternative assumption, however, arbitrageurs will not only take a long-short position in the two assets, but also start investing in both assets. The latter will simply push up the prices of both assets. We are not interested in analyzing this latter effect. Moreover, in the value premium example, for instance, it seems more natural to think that, after the discovery of the value premium, hedge funds start buying value stocks and shorting growth stocks, rather than hedge funds becoming aware of the existence of both value and growth stocks and starting to buy both of them.
} 
In the pre-discovery case, arbitrageurs are on the sidelines and have no impact on the markets for assets 1 and 2. Hence, the equilibrium can be defined as follows. The pre-discovery competitive equilibrium is defined as asset prices $\left(P_{i, t}\right.$ for $i=1,2$, and $\left.t=0,1\right)$ and investors' portfolios $\left(\theta_{i, t}\right.$ for $t=0,1$ and $i=1,2$ ), such that investors' portfolios optimize (4), and markets clear, i.e., for $i=1,2$ and $t=0,1$,

$$
W_{t} \theta_{i, t}=P_{i, t} .
$$

Similarly, the post-discovery competitive equilibrium is defined as asset prices $\left(P_{i, t}\right.$ for $i=1,2$, and $t=0,1)$ and portfolios of investors and arbitrageurs $\left(\theta_{i, t}\right.$ for $t=0,1$ and $i=1,2$; and $\theta_{i, t}^{a}$ for $t=0,1, i=1,2, e)$, such that investors' portfolios optimize (4), arbitrageurs' portfolios optimize (7), and markets clear, i.e., for $i=1,2$ and $t=0,1$,

$$
W_{t} \theta_{i, t}+W_{t}^{a} \theta_{i, t}^{a}=P_{i, t}
$$

The implicit assumption is that arbitrageurs do not have any hedging demand in asset 1 or 2. Moreover, after the discovery, they know that the cause of the anomaly is investors' hedging demand. These are simplifying assumptions. What is necessary is that arbitrageurs have less hedging demand in asset 1 than investors. Finally, even if arbitrageurs do not know the true cause of the anomaly, they will still invest in it, and the main implications in this alternative model remain similar to those in our current setup. ${ }^{6}$

\subsection{Equilibrium}

Proposition 1 (Pre-discovery) The pre-discovery equilibrium prices $P_{i, t}$ and portfolio choices $\theta_{i, t}$ can be characterized by equation (8) and

$$
E_{t}\left[\frac{r_{i, t+1}-1}{W_{t+1}+\rho P_{1, t+1}}\right]=0 \text {, for } i=1,2, t=0,1 \text {. }
$$

Moreover, in this equilibrium, we have $P_{1,0}<P_{2,0}$.

\footnotetext{
${ }^{6}$ See Brennan and Xia (2001) for an analysis of this intuition in the portfolio choice context.
} 
The above proposition illustrates the anomaly: Although both assets have the same fundamentals ex ante, they have different prices and hence different future expected returns. Due to their nontradable asset endowment, investors find asset 1 more risky than asset 2, leading to a lower price for asset 1 .

This is, of course, a reduced-form formulation of a risk-based anomaly. While traditional riskbased models focus on the detailed analysis of the exact mechanism through which the hedging demand arises, they assume away the discovery aspect since all investors know the return pattern all along. In contrast, we are not interested in the details of the hedging demand, but focus on the analysis of the consequences of the discovery. The following proposition characterizes the post-discovery equilibrium.

\section{Proposition 2 (Post-discovery) The post-discovery equilibrium prices $P_{i, t}$ and portfolio choices}

$\theta_{i, t}$ and $\theta_{i, 1}^{a}$ can be characterized by equations (5), (9), (10), and for $t=0,1$,

$$
\begin{aligned}
E_{t}\left[\frac{r_{1, t+1}-r_{2, t+1}}{W_{t+1}^{a}}\right] & =0 \\
E_{t}\left[\frac{r_{e, t+1}-1}{W_{t+1}^{a}}\right] & =0 .
\end{aligned}
$$

Since arbitrageurs are not exposed to the endowment risk that investors have, they find the anomaly an attractive investment opportunity, and buy asset 1 and short asset 2 . For convenience, we call the return from this long-short portfolio, $r_{1,1}-r_{2,1}$, the "anomaly return."

To analyze the discovery effect, we will compare the post-discovery equilibrium in Proposition 2 with the pre-discovery equilibrium in Proposition $1 .^{7}$ In particular, following the algorithm in Appendix A, we solve both equilibria numerically. The baseline parameter values are summarized

\footnotetext{
${ }^{7}$ The equation system in Proposition 2 is highly nonlinear and we have not been able to establish the existence and uniqueness of their solutions. However, we have always been able to solve the equation system numerically, and the solution appears to be unique. One might be somewhat surprised that the simple two-period structure in our model does not allow for a closed-form solution. In fact, the wealth effect in our model has similar complexity as that in the continuous-time model in Xiong (2001), which also heavily relies on numerical analysis. As noted in Gromb and Vayanos (2002), a two-period model of arbitrageurs and investors with a wealth effect is not as tractable as its appearance suggests (page 381). In a recent study, Kondor and Vayanos (2013) gain more tractability by simplifying investors' decisions.
} 
in Table 1. In the following numerical analysis, we vary only one parameter at a time to examine the effects of the discovery. We have also repeated our numerical analyses for other parameter values, and none of the following qualitative results are specific to the chosen parameters.

\subsection{Anomaly magnitude}

Figure 2 illustrates the effects of discovery on the expected anomaly returns. The dashed line represents the size of the anomaly (i.e., the expected anomaly return $E_{0}\left[r_{1,1}-r_{2,1}\right]$ ) before the discovery. Since arbitrageurs have no influence on the markets for assets 1 and 2 before the discovery, the dashed line is flat: The expected anomaly return is around $5.5 \%$ regardless of arbitrageurs' wealth.

After the discovery, arbitrageurs start exploiting the opportunity, reducing the expected anomaly return. As shown by the solid line in Panel A, the post-discovery expected anomaly return is lower than that in the pre-discovery case (i.e., the solid line is below the dashed line). In the case $W_{0}^{a}=2$, for example, the discovery reduces the expected anomaly return from $5.5 \%$ to $5 \%$.

The plot also shows that the effect of discovery is stronger when arbitrageurs have more wealth. For example, in the case $W_{0}^{a}=5$, the discovery reduces the expected anomaly return from $5.5 \%$ to $4 \%$. The discovery effect disappears when $W_{0}^{a}=0$. One can think of this $W_{0}^{a}=0$ case as representing the traditional modeling approach, where discovery does not change the set of investors who are aware of the anomaly.

Panels B and C demonstrate the effects of arbitrageurs' existing investment opportunity (i.e., asset $e$ ). If arbitrageurs' existing strategy is more attractive (i.e., $\mu_{e}$ is higher, or $\sigma_{e}$ is lower), they will allocate less capital to exploit the new anomaly and so its expected return will drop less. As shown in Panels B and C, after the discovery of an anomaly, its expected return is increasing in $\mu_{e}$ and decreasing in $\sigma_{e}$. 


\subsection{Correlation among anomaly returns}

By the construction of our model, before the discovery, the anomaly return $r_{1,1}-r_{2,1}$ is independent of the return of the existing anomaly $r_{e, 1}$. How does the discovery affect the correlation between $r_{1,1}-r_{2,1}$ and $r_{e, 1} ?$

Intuitively, after the discovery of an anomaly, arbitrageurs start exploiting it, as well as the existing anomaly, asset $e$. This creates a correlation through the wealth effect. Suppose the return from asset $e$ is unexpectedly high one period. This increases the wealth of these arbitrageurs. Everything else being equal, they will allocate more investment to the newly discovered anomaly. This higher investment pushes up the price of asset 1 and pushes down the price of asset 2, leading to a high anomaly return $r_{1,1}-r_{2,1}$. Similarly, an unexpectedly low return from asset $e$ leads to a low anomaly return. That is, the wealth effect increases the correlation between the newly discovered anomaly return and the return from the existing anomaly.

The above intuition is illustrated in Figure 3. Panel A plots the correlation coefficient between $r_{1,1}-r_{2,1}$ and $r_{e, 1}$. Before the discovery, as illustrated by the dashed line, the correlation is 0 . In contrast, the post-discovery correlation, shown by the solid line, is positive. The only exception is the case $W_{0}^{a}=0$, where the correlation is zero, the same as in the pre-discovery case. Again, one can view this special case as the traditional approach that abstracts away from discovery.

This discovery effect (i.e., the change in the correlation across the pre- and post-discovery cases) is initially increasing in the size of arbitrage capital $W_{0}^{a}$, and is not monotonic. This is because arbitrageurs have two effects on the correlation. The first is the aforementioned wealth effect, which increases the correlation. The second is that as arbitrage capital increases, the prices of assets 1 and 2 are more driven by their fundamentals. This reduces the correlation between $r_{1,1}-r_{2,1}$ and $r_{e, 1}$. When the size of arbitrage capital is sufficiently large, the second effect dominates, and hence a further increase in arbitrage capital reduces the correlation.

The above intuition is further illustrated in Panels B and C. In particular, when arbitrageurs 
have a larger position in asset $e$ (due to a higher $\mu_{e}$ or a lower $\sigma_{e}$ ), their wealth becomes more sensitive to its realized return $r_{e, 1}$. This leads to a stronger wealth effect, i.e., the discovery has a stronger effect in generating the correlation between $r_{1,1}-r_{2,1}$ and $r_{e, 1}$. In Panel B, for example, as the expected return from asset $e$ increases (i.e., a higher $\mu_{e}$ ), it leads to a higher correlation between $r_{1,1}-r_{2,1}$ and $r_{e, 1}$. Similarly, in Panel $\mathrm{C}$, as the volatility of asset $e$ increases (i.e., a higher $\sigma_{e}$ ), it leads to a weaker wealth effect and a lower correlation.

\subsection{Correlation between assets 1 and 2}

Our model shows that the discovery of an anomaly reduces the correlation coefficient between the returns of assets 1 and 2. The intuition is as follows. After the discovery, arbitrageurs long asset 1 and short asset 2 to exploit the anomaly. Now, suppose arbitrageurs' wealth increases due to, say, a high return from their investment in asset $e$. They will buy more of asset 1 and sell more of asset 2. This increases asset 1's return but decreases asset 2's return. Similarly, when arbitrageurs' wealth decreases, they will unwind some of their positions in the long-short portfolio. That is, they will sell asset 1 and buy asset 2, decreasing asset 1's return but increasing asset 2's return. In both cases, arbitrageurs' wealth shocks push the returns of the two assets to opposite directions, which reduces the correlation between the returns of assets 1 and 2 .

This intuition is illustrated in Figure 4. The dashed line in Panel A is for the pre-discovery correlation between assets 1 and 2. Since arbitrageurs are on the sidelines before the discovery, their wealth level $W_{0}^{a}$ does not affect the correlation. Hence, the dashed line is flat. The postdiscovery case is represented by the solid line. It is below the dashed line, suggesting that the discovery reduces the correlation between assets 1 and 2 . It also shows that the larger the size of arbitrage capital, the larger the reduction in the correlation.

The above intuition further suggests that the discovery effect is stronger when arbitrageurs' wealth is more volatile. To illustrate this intuition, we plot the correlation between assets 1 and 2 against arbitrageurs' wealth volatility. Specifically, we vary arbitrageurs' wealth volatility by 
changing $\sigma_{e}$, the volatility of asset $e$. The solid line in Panel B shows that after the discovery, the correlation between assets 1 and 2 is decreasing in arbitrageurs' wealth volatility. In contrast, this relation does not hold before the discovery, as shown by the dashed line.

\section{$3 \quad$ Mispricing-based anomaly}

Another major approach to understanding anomalies is based on mispricing. To compare mispricingand risk-based anomalies, we now analyze a model in which the anomaly is caused by investors' behavioral bias. Specifically, we modify the previous model by setting $\rho=0$; that is, there is no hedging demand. The fundamentals of the two assets are still given by (1) and (2). However, investors are biased about asset 1 and believe that for $t=0,1$,

$$
\mu_{1, t+1}= \begin{cases}\mu+\sigma & \text { with probability } p-b, \\ \mu-\sigma & \text { with probability } p+b,\end{cases}
$$

where $0 \leq b<p$. That is, investors underestimate asset 1's expected cash flow, and $b$ measures the degree of the bias. In contrast, their belief about asset 2 is correct.

Investors' objective is to choose $\theta_{i, t}$, for $i=1,2$, and $t=0,1$, to

$$
\max _{\theta_{i, t}} E_{0}^{*}\left[\log \left(W_{2}\right)\right]
$$

subject to (3), where $E_{0}^{*}[\cdot]$ indicates that the expectation is taken under the biased belief in (11). Arbitrageurs have correct beliefs, and their objective is given by (7), as in the previous section.

This formulation is meant to capture the essence of mispricing-based interpretations of anomalies in a reduced form. For instance, in the value premium example, Lakonishok, Shleifer, and Vishny (1994) argue that investors are overly enthusiastic about glamorous growth stocks and have a low demand for value stocks. Similarly, in our model, investors underestimate the payoff from asset 1 and so have a low demand.

Similar to the case for the risk-based anomaly, in the pre-discovery case, arbitrageurs have no influence on the markets for assets 1 and 2. The competitive equilibrium for this case is defined as 
asset prices $\left(P_{i, t}\right.$ for $i=1,2$, and $\left.t=0,1\right)$ and investors' portfolios $\left(\theta_{i, t}\right.$ for $t=0,1$ and $\left.i=1,2\right)$, such that investors' portfolios optimize (12), and markets clear as in (8).

The post-discovery competitive equilibrium is defined as asset prices $\left(P_{i, t}\right.$ for $i=1,2$, and $t=0,1)$ and portfolios of investors and arbitrageurs $\left(\theta_{i, t}\right.$ for $t=0,1$ and $i=1,2$; and $\theta_{i, t}^{a}$ for $t=0,1, i=1,2, e)$, such that investors' portfolios optimize (12), arbitrageurs' portfolios optimize (7), and markets clear as in (9).

What is implicitly assumed here is that the discovery does not affect investors' bias $b$. That is, the bias is systematic and deeply rooted, and investors do not adjust their behavior after the discovery of the anomaly.

Proposition 3 The pre-discovery equilibrium prices $P_{i, t}$ and portfolio choices $\theta_{i, t}$ can be characterized by (8), and for $i=1,2, t=0,1$,

$$
E_{t}^{*}\left[\frac{r_{i, t+1}-1}{W_{t+1}}\right]=0
$$

The post-discovery equilibrium prices $P_{i, t}$ and portfolio choices $\left(\theta_{i, t}\right.$, and $\left.\theta_{i, 1}^{a}\right)$ can be characterized by equations (5), (9), (13), and for $t=0,1$,

$$
\begin{aligned}
E_{t}\left[\frac{r_{1, t+1}-r_{2, t+1}}{W_{t+1}^{a}}\right] & =0 \\
E_{t}\left[\frac{r_{e, t+1}-1}{W_{t+1}^{a}}\right] & =0 .
\end{aligned}
$$

Similar to the risk-based case in the previous section, investors have a lower demand for asset 1 than for asset 2. The only difference is the motivation. In the risk-based case, the motivation is to hedge, while in the mispricing-based case, the motivation is investors' wrong belief. Can we distinguish a risk-based anomaly from a mispricing-based one by examining asset prices? We will examine this in the next section. 


\subsection{Comparing risk- and mispricing-based anomalies}

We now compare the risk-based anomaly (Propositions 1 and 2) with the mispricing-based one (Proposition 3). In particular, we set $b=0.055$ and adopt all other parameters from Table 1 . We choose this value for $b$ so that, before the discovery, the expected anomaly returns are the same across the risk-based case and the mispricing-based case. We now compare the post-discovery return dynamic across the two cases.

Panel A of Figure 5 shows that it is difficult to distinguish a risk-based anomaly from a mispricing-based one by examining the post-discovery performance. The solid and dashed lines represent the post-discovery expected anomaly return for the risk- and mispricing-based cases, respectively. The pre-discovery expected anomaly return for both cases is flat at around 5.5\% (we omitted this flat line). The plot shows that the discovery of an anomaly reduces its expected return regardless of whether the anomaly is caused by risk or mispricing. Moreover, both lines are downward sloping, implying that the more arbitrage capital $\left(W_{0}^{a}\right)$, the stronger the effect. The two lines are also close to each other, suggesting that the magnitude of the reduction of the anomaly return is similar across the two cases. Panel B shows that, for both the risk- and mispricing-based cases, the discovery of an anomaly increases the correlation between its return and the existing anomaly return. Even the non-monotonic pattern is similar across the two cases. Finally, Panel $\mathrm{C}$ shows that the discovery of the anomaly reduces the correlation between assets 1 and 2 for both risk- and mispricing-based cases. Moreover, this correlation is decreasing in arbitrageurs' wealth level $W_{0}^{a}$ in both cases.

\subsection{One possible solution}

The above results highlight the difficulty in distinguishing between risk- and mispricing-based anomalies by examining asset prices. ${ }^{8}$ What is the solution then? We argue that it is more

\footnotetext{
${ }^{8}$ This is parallel to the result in Brav and Heaton (2002), which emphasizes the difficulty in distinguishing a biased belief from a rational belief with structural uncertainty.
} 
promising to analyze investors' portfolios. The idea is that investors' holdings might offer direct evidence on why they overweight one asset and underweight another.

In a risk-based anomaly, investors recognize the fact that asset 1's expected return is higher than asset 2's, and so they have a higher total exposure to asset 1 than to asset 2, once we include the exposure implied by their nontradable endowment. That is, in this case, although investors underweight asset 1 in the stock market, their total exposure to asset 1 is actually higher than that to asset 2. In a mispricing-based anomaly, however, investors have a lower exposure to asset 1, because they mistakenly believe that it has a lower future payoff and underweight it.

Therefore, investors' portfolio holdings can help separate risk- and mispricing-based anomalies. For example, Fama and French $(1993,1996)$ interpret the value premium as value stocks exposing investors to risks associated with economy-wide financial distress. To evaluate this risk-based explanation, one can examine whether the investors who underweight value stocks are those who are more exposed to risk of financial distress (e.g., their labor income or other assets are more exposed to financial distress).

To be fair, while examining portfolio holdings is a direct approach, it is very demanding on the dataset. It requires detailed information on investors' positions, including their nontradable assets. Nevertheless, in this big data era, it is hopeful that as more micro-level data on investors' holdings become available, this test may eventually become feasible. ${ }^{9}$ For example, Betermier, Calvet, and Sodini (2014) has recently analyzed the characteristics of investors of value and growth stocks, and potentially shed light on why investors hold value or growth stocks.

\footnotetext{
${ }^{9}$ This idea can be applied more broadly to the measurement of many other hard-to-measure variables. For example, Choi, Jin, and Yan (2014) tries to measure the degree of information asymmetry at an individual stock level by tracking the activities of all investors in the stock market in China. The detailed transaction data of the whole population reveals the degree of information asymmetry for each stock.
} 


\subsection{Welfare}

How does the discovery of an anomaly affect investor welfare? To address this question, we first need to clarify our welfare measures. For the risk-based case, we simply use investors' expected utility at $t=0$. For the mispricing-based case, we use "subjective welfare" to refer to investors' subjective expected utility at $t=0$, and use "objective welfare" to refer to investors' utility evaluated under the objective belief at $t=0$.

Proposition 4 The discovery of a risk-based anomaly increases investors' welfare. The discovery of a mispricing-based anomaly increases investors' subjective welfare, but reduces their objective welfare.

In the case of a risk-based anomaly, arbitrageurs essentially offer better risk sharing to investors. Before the discovery, the endowment risk is narrowly shared among investors (i.e., arbitrageurs are not involved). After the discovery, this endowment risk is shared between investors and arbitrageurs: Investors unload asset 1 to arbitrageurs to hedge against their endowment risk. Arbitrageurs' trading makes the hedging cheaper. For the mispricing-based case, when arbitrageurs start exploiting the anomaly, naive investors think they are better off, since they can offload some of asset 1, which they are pessimistic about. That is, investors' subjective expected utility increases after the discovery. However, the discovery reduces naive investors' objective welfare. For instance, suppose the value premium was caused by investors' overly optimistic perception about growth stocks. The discovery of this anomaly attracts arbitrageurs to buy value and sell growth stocks. Consequently, investors end up holding more over-priced growth stocks and fewer under-priced value stocks, and they will suffer from worse performance in the future. 


\section{Empirical analysis}

Our risk-based model in Section 2 and mispricing-based model in Section 3 share the following three main predictions: The discovery of an anomaly i) reduces its magnitude, ii) increases its correlation with existing anomalies, and iii) reduces the correlation between assets 1 and 2 . The first two predictions are consistent with existing empirical evidence. For example, McLean and Pontiff (2013) analyze the post-discovery performances of 82 anomalies that have been identified in published academic studies. They find that post-discovery anomaly returns decay by $44 \%$ on average. In addition, they find that after the discovery, the return of the new anomaly becomes more correlated with the returns from existing anomalies.

The third prediction is new to the literature, and so we empirically examine it in this section. According to Harvey, Liu, and Zhu (2014), there are more than 300 anomalies documented in the academic literature. However, one would expect that for a discovery to have a significant effect on underlying stock prices, the anomaly needs to be widely known and exploited by a large number of arbitrageurs. Hence, in the next section, we examine the three arguably most well-known anomalies - momentum, size, and value - one by one. Then, in Section 4.2, we study a larger set of anomalies as a group.

\subsection{Momentum, size, and value}

Our goal is to examine, for each anomaly, whether the correlation coefficient between the excess returns of deciles 1 and 10 decreases after the discovery of the anomaly. ${ }^{10}$ It is not obvious how to choose the "discovery time" for each anomaly. The decision is necessarily subjective to some extent. Suppose we choose the publication time of the first study on the anomaly. One might object to this choice because it is possible that practitioners have known and exploited

\footnotetext{
${ }^{10}$ Lou and Polk (2013) uses the high-frequency correlation among stocks to infer the size of arbitrage capital. The economic mechanism is quite different. In their setup, higher high-frequency correlations among stocks imply a larger arbitrage capital size. However, in our setup, higher low-frequency correlations between decile 1 and 10 portfolios imply a smaller arbitrage capital size.
} 
the anomaly before that. Moreover, the essence of the "discovery time" is the time when a large number of arbitrageurs start exploiting the anomaly. One might suspect that it may take some time after arbitrageurs become aware of an anomaly for them to be convinced and start exploiting it. Moreover, the first publication might not be the one that generates most attention. For example, the discovery of the size and value anomalies are usually credited to Banz (1981) and Basu (1983), respectively. However, one might suspect that Fama and French (1992) has generated more attention on these two anomalies. For example, the last column of Table 2 reports the citation counts for each paper according to Google Scholar as of October 16, 2014. One can see that the citation for Fama and French (1992) is an order of magnitude larger than those for Banz (1981) and Basu (1983). Moreover, Fama and French's studies in the early 1990s suggest that the long list of anomalies at that time can be narrowed down to size and value, giving these two anomalies extra attention.

With the above considerations in mind, we use September 1981 (Banz (1981)) and June 1992 (Fama and French (1992)) as possible discovery times for the size anomaly, June 1983 (Basu (1983)) and June 1992 (Fama and French (1992)) as possible discovery times for the value anomaly, and March 1993 as the discovery time for momentum (Jegadeesh and Titman (1993)).

We obtain the monthly decile portfolio returns and risk-free asset returns during 1927-2013 from Kenneth French's website. Panel A of Figure 1 is the time series of the correlation coefficients between the excess returns from deciles 1 and 10 of momentum portfolios, estimated based on a rolling window of previous five years' data. In the first six decades, this correlation fluctuated between 0.6 and 0.8. In the early 1990s, however, it dropped significantly to around 0.4. The significant decline in the correlation coincided with the publication of the most influential study on momentum, Jegadeesh and Titman (1993). Although we cannot infer causality, this change in correlation is certainly consistent with our model prediction. Similarly, Panels B and C are the correlation coefficients for size and value anomalies, respectively. Interestingly, although these two anomalies were documented in the early 1980s, the correlations started dropping sharply in 
the early 1990s. This coincides with Fama and French's influential work that singles out size and value among a number of anomalies. We note that in Panels $\mathrm{B}$ and $\mathrm{C}$, the correlations revert back to their pre-discovery level after 2000. While the recent financial crisis might have contributed to the higher correlations in the last few years, it certainly cannot explain this drastic increase in the correlations for these two anomalies in the last 10 years.

To formally test whether the correlations decrease after discoveries, we normalize the correlations between deciles 1 and 10 by the correlations between deciles 5 and 6 , in order to control for a potential time trend for the correlation among stocks in general. The motivation is the following. To exploit the anomaly return, arbitrageurs are likely to take larger long-short positions in deciles 1 and 10 than in deciles 5 and 6 . Hence, the correlation between deciles 5 and 6 may share a common time trend with the correlation between deciles 1 and 10, but should be subject to a weaker discovery effect. For each anomaly, we compute the correlation ratio as

$$
X_{t} \equiv \frac{\rho_{t}^{1,10}}{\rho_{t}^{5,6}},
$$

where $\rho_{t}^{1,10}$ is the correlation coefficient between the monthly excess returns of deciles 1 and 10 of the anomaly during the five years prior to month $t$, and $\rho_{t}^{5,6}$ is similarly defined for deciles 5 and 6 .

Table 3 reports the summary statistics of the estimated correlation ratios. The first column of Panel A shows that, for momentum, the correlation ratio has a mean of 0.55 , and standard deviation of 0.08 . The correlation ratio is slightly higher (0.66 and 0.75$)$ and more volatile $(0.21$ and 0.11 ) for size and value anomalies, respectively. For each of the three series, the mean and median are close to each other.

To test our model prediction, for each anomaly, we regress the ratio $X_{t}$ on Discovery, a dummy variable that takes the value of 0 before the discovery of the anomaly and 1 afterwards. For the momentum anomaly, for example, we use March 1993 (the publication time of Jegadeesh and Titman (1993)) as the discovery time. The first column of Table 4 shows that the coefficient 
for the discovery dummy is -0.13 , with a $t$-statistic of -3.97 . This suggests that, for momentum, the correlation ratio decreases by 0.13 after the discovery of the anomaly.

For the size anomaly, as discussed earlier, we analyze two potential discovery times, September 1981 and June 1992. If we use the former as the discovery time, as shown in the second column, the coefficient of the discovery dummy is negative, but statistically insignificant. Once we use June 1992 as the discovery time, however, the result gets stronger: The point estimate becomes twice as large, -0.14 , with a $t$-statistic of -1.78 . Similarly, for the value anomaly, the coefficient for the discovery dummy is -0.09 , only marginally significant, if we use June 1983 as the discovery time (column 4). Once we use June 1992 as the discovery time, the point estimate becomes -0.13 , with a $t$-statistic of -1.96 . These results are consistent with the observation from the plots in Figure 1. There is no immediate decrease in the correlation coefficient after the original studies (Banz (1981) and Basu (1983)). Perhaps due to the wider influence of Fama and French (1992), and/or the rapid growth of the hedge fund industry, the correlations decrease significantly in the early 1990s.

The essential point of our model is that arbitrageurs' trading activity reduces the correlation between deciles 1 and 10. We now examine more directly whether this correlation is indeed related to arbitrageurs' activity. Our model implies that the post-discovery correlation between deciles 1 and 10 is decreasing in the volatility of arbitrageurs' wealth. Note that this prediction is the opposite of the implication from the casual intuition that arbitrageurs' wealth tends to be more volatile when the market is more volatile (e.g., in a financial crisis). Since stocks tend to be more correlated when the market is more volatile, this casual intuition implies that the correlation between deciles 1 and 10 should be increasing in the volatility of arbitrageurs' wealth.

To test our model implication, we need a proxy for the volatility of arbitrageurs' wealth. It is certainly impossible to directly observe the aggregate wealth of all arbitrageurs. As a compromise, we measure the wealth of one group of investors, who are often considered to be arbitrageurs in financial markets: hedge funds. The implicit assumption is that the volatility of the aggregate 
wealth of all hedge funds is positively correlated with the volatility of the total wealth of all arbitrageurs.

We obtain monthly hedge fund returns and assets under management (AUM) from TASS during 1994-2012. Then, we compute the percentage change in AUM for each fund and aggregate them into the value-weighted average of percentage AUM change of all funds. For each month

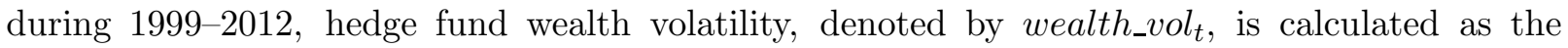
standard deviation of this aggregate AUM percentage changes during the previous 5 years. The summary statistics for wealth_vol $t$ are reported in Panel B of Table 3. This series has a mean of 0.032 and a standard deviation of 0.005 . The median is 0.031 , nearly identical to the mean.

The first column of each panel of Table 5 reports the regression results of the correlation ratio

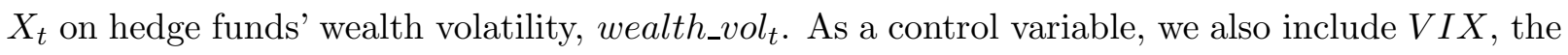
implied volatility of S\&P 500 index options on the Chicago Board Options Exchange in the current

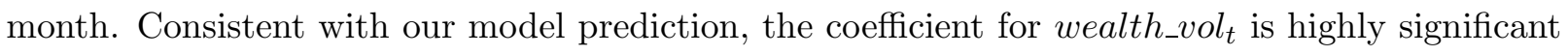
for all three anomalies: The coefficient estimates are $-6.78(t=-2.23),-37.31(t=-6.25)$, and $-17.62(t=-6.74)$, for momentum, size, and value, respectively. $V I X$ is considered to be negatively related to the amount of arbitrage capital in the market (e.g., Brunnermeier and Pedersen (2009)). Hence, a higher VIX is correlated with less arbitrage capital, which implies a higher $X$. In our estimates in Panels $\mathrm{B}$ and $\mathrm{C}$, the coefficient for $V I X$ is highly positively significant, although the estimate for momentum in Panel A is insignificant.

The AUM change can be decomposed into two components: the first is due to performance and the second is due to fund flows from investors. Similar to the construction of wealth_vol , we compute the volatility of each component. For each month, we use the data from the previous 5 years to estimate the standard deviation of the monthly value-weighted hedge fund returns, ret_vol, and the standard deviation of the monthly percentage flows to the hedge fund industry,

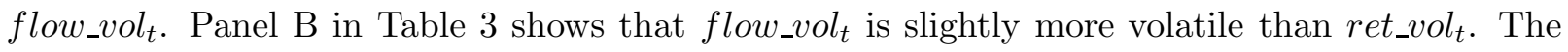
correlation coefficient between these two components is 0.51 , as shown in Panel C. It also shows 
that both flow_vol $_{t}$ and ret_vol $t_{t}$ are negatively correlated to the correlation ratio $X$ for all three anomalies.

We regress $X_{t}$ on ret_vol flow_vol $_{t}$, and $V I X_{t}$ for each anomaly. The results are reported in Table 5. The second and third columns of Panels A-C show that, if we only include one

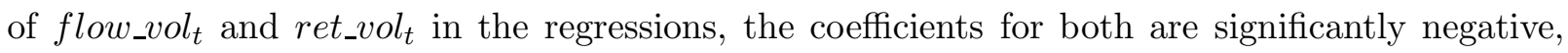
with one exception of flow_vol $l_{t}$ for momentum. Including both flow_vol $l_{t}$ and ret_vol $t$ in the regressions, we find that for momentum, the return-induced volatility ret_vol $t_{t}$ is more correlated with $X_{t}$, while for size and value, the fund-flow-induced volatility flow_vol $l_{t}$ is more correlated with $X_{t}$.

We conduct a variety of robustness analyses, and the main results remain similar throughout.

First, we use the correlation estimate $\rho_{t}^{1,10}$ to replace the correlation ratio $X_{t}$ to conduct our analysis. Second, we use the average correlation of 1000 pairs of simulated random decile portfolios to replace $\rho_{t}^{5,6}$ in our construction of $X_{t}$. Third, we use a 3 -year rolling window (rather than the 5 -year rolling window in the above analysis) to estimate the correlation ratios in equation (16). Forth, we use quintile portfolios to construct the correlation ratio: the correlation coefficient between quintiles 1 and 5 divided by the correlation coefficient between quintiles 2 and 4 . Finally, we use the index return from Hedge Fund Research (rather than the one we constructed from TASS) for our regressions in Table 5.

\subsection{More anomalies}

We now expand our analysis to a broader set of anomalies. Apart from a robustness check for the previous results, a broader set of anomalies also offers a stronger test of our model prediction. For example, for all three anomalies in the previous section, the decrease in correlation occurred in the early 1990s. This is consistent with the interpretation that those three anomalies became more widely known in the early 1990s, perhaps combined with the rapid growth of the hedge fund industry around that time. However, a broader set of anomalies offers an opportunity to test our 
model prediction for discoveries at different points in time.

More importantly, this broader set of anomalies offers an opportunity to have a stronger test of our model. In particular, our model (Panel B of Figure 4) implies that the post-discovery correlation between deciles 1 and 10 is decreasing in the volatility of arbitrageurs' wealth, but this relation does not hold before the discovery. In our analysis in Section 4.1, we cannot test the pre-discovery part, because our hedge fund data start in 1999, long after the discovery of value, growth, and momentum. By including anomalies discovered after 1999, we have a chance to further test this model prediction.

We choose the list of anomalies that are studied in Stambaugh, Yu, and Yuan (2012). In addition to the three anomalies analyzed earlier, the list also includes ten other influential anomalies discovered in the last four decades. Table 2 lists all the anomalies and the papers that are credited for their discovery. The last column of this table reports the citation counts for each study. One can see that all ten studies are heavily cited in the literature. These ten anomalies reflect portfolio sorts on measures that include financial distress, net stock issues, composite equity issues, total accruals, net operating assets, gross profit-to-assets, asset growth, return-on-assets, and investment-to-assets. The publication time of those studies ranges from 1980 to 2013. For these ten anomalies, we simply use the corresponding paper's publication time, listed in the third column of Table 2, as the discovery time.

We exclude the gross profitability anomaly in Novy-Marx (2013) due to the lack of postdiscovery data. Then, we pool the rest of the nine anomalies and the three in the previous section together, and run a panel regression of the correlation ratio $X_{t}$, defined in (16), on the dummy variable Discovery. Table 6 shows that the coefficient for Discovery is $-0.052(t=-1.91)$, implying that, on average, the discovery of an anomaly reduces the correlation ratio by 0.052 .

To test the implication on the relation between the correlation and hedge funds' activity, we

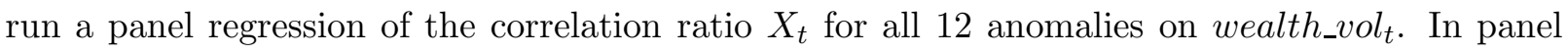


A of Table 7, the regression includes the entire available sample during 1999-2012. Note that half of the 12 anomalies were discovered after 1999. Hence, this regression includes pre-discovery data for $X_{t}$ for 6 anomalies. In contrast, in the regression in Panel B, we exclude those prediscovery data for the 6 anomalies that were discovered after 1999. Our model (Panel B of Figure

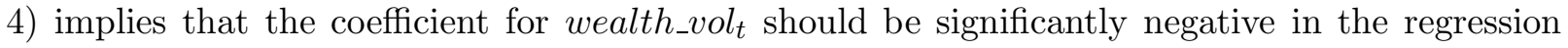
for the post-discovery sample in Panel B, and that this result should be weaker in Panel A. This is exactly what we find. As shown in the first column of the two panels, the estimate for the coefficient of wealth_vol $_{t}$ is $-4.18(t=-1.00)$ in the Panel A, and $-11.75(t=-2.21)$ in Panel B. Similarly, the decomposition results in the rest of the table show that the coefficients for ret_vol $t_{t}$ and flow_vol $l_{t}$ are strongly negative in the post-discovery sample in Panel B but insignificant in the overall sample in Panel A.

We also examine the robustness of the results in Table 7. Given that the standard errors are clustered on anomaly and there are only 12 anomalies, we also run the test with an alternative specification. In particular, for each month, we compute the average of the correlation ratios across anomalies. Then we run a time-series regression of the average correlation ratio on wealth_vol, ret_vol, and flow_vol. The results are reported in Table 8. In Panel A, the regression is based on the entire available sample during 1999-2012. In Panel B, however, we include only the postdiscovery sample. The results remain similar to those in Table 7: Compared to the estimates in the overall sample, the coefficients of hedge fund wealth volatility in the post-discovery sample are larger in magnitude and more statistically significant. For example, the coefficient for wealth_vol $t$ is $-4.18(t=-4.81)$ in the overall sample in Panel A and is $-15.88(t=-16.24)$ in the postdiscovery sample in Panel B.

\section{Conclusion}

We have analyzed a simple model of anomaly discovery. It shows that consistent with existing evidence, the discovery of an anomaly reduces its magnitude and makes its returns more cor- 
related with the returns from existing anomalies. A new prediction is that the discovery of an anomaly reduces the correlation between the two extreme portfolios formed from the corresponding portfolio sorting for that anomaly, and this effect is stronger when arbitrageurs' wealth is more volatile. We empirically test these new predictions for 12 widely-known anomalies, and find strong evidence consistent with our model predictions.

Our analysis also contrasts risk- with mispricing-based anomalies, and highlights the difficulty in distinguishing between them by examining asset prices. We argue that one solution is to analyze investors' portfolios instead. For the value premium, for example, we can examine the exposures of those investors who underweight value stocks and overweight growth stocks. We can test whether those investors appear to be more exposed to the risk proposed in the explanation. While this direct approach is demanding on the required dataset, in this big data era, it might not be a fantasy, either.

Our goal in this paper is to highlight the importance of the discovery aspect, both conceptually and quantitatively. Hence, we take a simplified approach in our model by comparing the preand post-discovery equilibria. This leaves many interesting questions unanswered. For example, it seems natural to conjecture that the statistical significance of the discovered return pattern determines the "legitimacy" of the anomaly and whether it will prompt arbitrageurs to act. The dynamics of the interaction between the legitimacy of an anomaly, arbitrageurs' actions, and asset prices seems a promising avenue for future research. 


\section{References}

[1] Asness, C., Frazzini, A., Israel, R., Moskowitz, T. (2014). "Fact, Fiction and Momentum Investing," Journal of Portfolio Management, forthcoming.

[2] Baker, M., Wurgler, J. (2006). "Investor sentiment and the cross-section of stock returns," Journal of Finance, 1645-1680.

[3] Bansal, R., Dittmar R., Lundblad, C. (2005). "Consumption, dividends, and the cross section of equity returns," Journal of Finance, 60, 1639-1672.

[4] Banz, R. W., (1981). "The Relationship between Return and Market Value of Common Stocks," Journal of Financial Economics, 9, 3-18.

[5] Basak, S., Croitoru, B. (2006). "On the Role of Arbitrageurs in Rational Markets," Journal of Financial Economics, 81, 143-173.

[6] Basu, S. (1983). "The Relationship Between Earnings' Yield, Market Value and Return for NYSE Common Stocks: Furhter Evidence," Journal of Financial Economics, 12, 129-156.

[7] Betermier, S., Calvet, L., Sodini, P. (2014). "Who are the Value and Growth Investors?" working paper.

[8] Brav, A., Heaton, J. B. (2002). "Competing Theories of Financial Anomalies," Review of Financial Studies, 15, 575-606.

[9] Brennan, M., Xia, Y. (2001). "Assessing Asset Pricing Anomalies," Review of Financial Studies, 14, 905-942.

[10] Brunnermeier, M., Pedersen, L. (2009). "Market Liquidity and Funding Liquidity," Review of Financial Studies, 22, 2201-2238.

[11] Campbell, J. Y., Hilscher, J., Szilagyi, J. (2008). "In Search of Distress Risk," Journal of Finance, 63, 2899-2939.

[12] Chordia, T., Subrahmanyam, A., Tong, Q. (2013). "Trends in the Cross-section of Expected Stock Returns," working paper.

[13] Chinco, A. (2014). "Feature-Selection Risk," working paper.

[14] Choi, J., Jin L., Yan, H. (2014), "Informed Trading and the Cost of Capital," working paper.

[15] Cochrane, J. H. (1999). "Portfolio Advice for a Multifactor World," Economic Perspectives Federal Reserve Bank of Chicago, 23, 59-78.

[16] Cooper, M. J., Gulen, H., Schill, M. J. (2008). "Asset Growth and the Cross-Section of Stock Returns," Journal of Finance, 63, 1609-1652.

[17] Daniel, K. D., Titman, S. (2006). "Market Reactions to Tangible and Intangible Information," Journal of Finance, 61, 1605-1643. 
[18] Dow, J., Gorton G. (1994). "Arbitrage Chains," Journal of Finance, 49, 819-849.

[19] Drechsler, I., Drechsler, Q. (2014). "The Shorting Premium and Asset Pricing Anomalies," working paper.

[20] Fama, E., French, K. (1992). "The Cross-section of Expected Stock Returns," Journal of Finance 47, 427-465.

[21] Fama, E. F., French, K. (1993). "Common Risk Factors in the Returns on Stocks and Bonds," Journal of Financial Economics, 33, 3-56.

[22] Fama, E., French, K. (1996). "Multifactor Explanations of Asset Pricing Anomalies," Journal of Finance, 51, 55-84.

[23] Fama, E., French, K. (2006). "Profitability, Investment, and Average Returns," Journal of Financial Economics, 82, 491-518.

[24] Green, J., Hand, J., Zhang, X. F. (2013). "The Surpraview of Return Predictive Signals," Review of Accounting Studies, 18, 692-730.

[25] Gromb, D., Vayanos, D. (2002). "Equilibrium and Welfare in Markets with Financially Constrained Arbitrageurs," Journal of financial Economics, 66, 361-407.

[26] Harvey, C., Liu, Y., Zhu, H. (2014). "and the Cross-Section of Expected Returns," working paper.

[27] He, Z., Krishnamurthy, A. (2013). "Intermediary Asset Pricing," American Economic Review, $103,732-770$.

[28] Hirshleifer, D., Hou, K., Teoh, S. H., Zhang, Y. (2011). "Do Investors Over- value Firms with Bloated Balance Sheets," Journal of Accounting and Economics, 38, 297-331.

[29] Hou, K., Xue, C., Zhang L. (2014). "Digesting Anomalies: An Investment Approach," Review of Financial Studies, forthcoming.

[30] Jegadeesh, N., Titman, S. (1993). "Returns to Buying Winners and Selling Losers: Implications for Market Efficiency," Journal of Finance, 48, 65-91.

[31] Jegadeesh, N., Titman, S. (2001). "Profitability of Momentum Strategies: An Evaluation of Alternative Explanations," Journal of Finance, 56, 699-720.

[32] Johnson, W., Schwartz, W. (2000). "Evidence that Capital Markets Learn From Academic Research: Earnings Surprises and the Persistence of Post-announcement Drift," working paper.

[33] Kondor, P. (2009). "Risk in Dynamic Arbitrage: Price Effects of Convergence Trading," Journal of Finance, 64, 638-658.

[34] Kondor, P., Vayanos, D. (2013). "Liquidity Risk and the Dynamics of Arbitrage Capital," working paper. 
[35] Kyle, A., Xiong, W. (2001). "Contagion as a Wealth Effect of Financial Intermediaries," Journal of Finance, 56, 1401-1440.

[36] Lakonishok, J., Shleifer, A., Vishny, R. (1994). "Contrarian Investment, Extrapolation and Risk," Journal of Finance, 49, 1541-1578.

[37] Liu, J., Longstaff, F. (2004). "Losing Money on Arbitrages: Optimal Dynamic Portfolio Choice in Markets with Arbitrage Opportunities," Review of Financial Studies, 17, 611-641.

[38] Lou, D., Polk, C. (2013). "Comomentum: Inferring Arbitrage Activity from Return Correlations", working paper.

[39] McLean, R. D., Pontiff, J. (2013). "Does Academic Research Destroy Stock Return Predictability?" working paper.

[40] Novy-Marx, R. (2010). "The Other Side of Value: Good Growth and the Gross Profitability Premium," working paper.

[41] Ohlson, J. A. (1980). "Financial Ratios and the Probabilistic Prediction of Bankruptcy," Journal of Accounting Research, 18, 109-131.

[42] Ritter, J. R. (1991). "The Long-run Performance of Initial Public Offerings," Journal of Finance, 46, 3-27.

[43] Schwert, G. W. (2003). "Anomalies and Market Efficiency," Handbook of the Economics of Finance, 1, 939-974.

[44] Shleifer, A., Vishny, R. (1997). "The Limits of Arbitrage," Journal of Finance, 52, 35-55.

[45] Sloan, R. G. (1996). "Do Stock Prices Fully Reflect Information in Accruals and Cash Flows about Future Earnings?," Accounting Review, 71, 289-315.

[46] Stambaugh. R., Yu, J., Yuan, Y. (2012). "The Short of It: Investor Sentiment and Anomalies," Journal of Financial Economics, 104, 288-302.

[47] Stambaugh. R., Yu, J., Yuan, Y. (2014). "Arbitrage Asymmetry and the Idiosyncratic Volatility Puzzle," Journal of Finance,, Forthcoming.

[48] Titman. S., Wei, K., Xie, F. (2004). "Capital Investments and Stock Returns," Journal of Financial and Quantitative Analysis, 39, 677-700.

[49] Vayanos, D., Woolley, P., (2013). "An Institutional Theory of Momentum and Reversal," Review of Financial Studies, 2013, 1087-1145.

[50] Xiong, W. (2001). "Convergence Trading with Wealth Effects," Journal of Financial Economics, 62, 247-292. 


\section{Appendix A. Numerical procedure}

We follow the procedure described below to solve the model:

1. Take initial guesses for the total wealth for investors and arbitrageurs at $t=1$ : $W_{1}$ and $W_{1}^{a}$ for the eight states at date 1.

2. For each of the eight states, take $W_{1}$ and $W_{1}^{a}$ as given, solve for the portfolios $\left(\theta_{i, 1}\right.$ for $i=1,2$, and $\theta_{i, 1}^{a}$ for $\left.i=1,2, e\right)$ and prices $P_{1,1}$ and $P_{2,1}$.

3. Take the prices $P_{1,1}$ and $P_{2,1}$ for the eight states in step 2 as given, solve for the $t=0$ portfolios $\left(\theta_{i, 0}\right.$ for $i=1,2$, and $\theta_{i, 0}^{a}$ for $\left.i=1,2, e\right)$ and prices $P_{1,0}$ and $P_{2,0}$.

4. Based on the portfolios in step $3\left(\theta_{i, 0}\right.$ for $i=1,2$, and $\theta_{i, 0}^{a}$ for $\left.i=1,2, e\right)$ and the prices in steps 2 and $3\left(P_{1,0}, P_{2,0}\right.$, and $P_{1,1}, P_{2,1}$ for all eight states at $\left.t=1\right)$, calculate the investors' and arbitrageurs' updated wealth, $W_{1}$ and $W_{1}^{a}$, in the eight cases at $t=1$.

5. Repeat steps 2 to 4 until the wealth, portfolios, and prices converge, i.e., for each variable, the difference between two iterations is no greater than 0.00005 .

\section{Appendix B. Proofs}

\section{Proof of Propositions 1 and 2}

Due to the logarithmic preference, the maximization problem (4) is equivalent to maximizing the $\log$ wealth growth for each period. Hence, investors' first-order conditions are given by

$$
E_{t}\left[\frac{r_{i, t+1}-1}{W_{t+1}+\rho P_{1, t+1}}\right]=0,
$$

for $i=1,2, t=0,1$. Similarly, the arbitrageurs' optimization problem (7) can also be decomposed into a period-by-period optimization problem, and the first-order conditions are given by

$$
\begin{aligned}
E_{t}\left[\frac{r_{1, t+1}-r_{2, t+1}}{W_{t+1}^{a}}\right] & =0, \\
E_{t}\left[\frac{r_{a, t+1}-1}{W_{t+1}^{a}}\right] & =0 .
\end{aligned}
$$

Combining the above first-order conditions with the market-clearing conditions, we can characterize the equilibria in Propositions 1 and 2. 
We now prove $P_{1,0}<P_{2,0}$ by contradiction. Suppose $P_{1,0} \geq P_{2,0}$. Note that investors' optimal portfolio in equilibrium is to hold one unit of both assets. Suppose an investor sells $\epsilon$ unit of asset 1 and buys $\epsilon$ unit of asset 2. Define his expected utility as

$$
U(\epsilon) \equiv E_{0}\left[\log \left(k+(1+\rho-\epsilon) D_{1,2}+(1+\epsilon) D_{2,2}\right)\right] .
$$

It is easy to see that $\left.\frac{d U}{d \epsilon}\right|_{\epsilon=0}>0$. That is, he can strictly improve his portfolio by selling $\epsilon$ unit of asset 1 and buying $\epsilon$ unit of asset 2 . This leads to a contradiction.

\section{Proof of Propositions 3}

The first-order condition to the maximization problem (12) is given by (13). The first-order conditions for arbitrageurs are still given by (14) and (15). These optimality and market-clearing conditions lead to the results in the proposition.

\section{Proof of Proposition 4}

In both the risk-based and mispricing-based cases, investors have the option not to trade. The participation constraint implies that the investors' expected utility cannot be lower than that in the pre-discovery case. Moreover, investors' concave utility function and convex budget constraint imply that the investors' optimization problem has a unique solution. It is easy to see that in the case of $W_{0}^{a}>0$, the portfolio characterized in Proposition 2 is strictly different from the non-participation portfolio. Hence, discovery strictly increases investor welfare. Similarly, in the mispricing-based case, discovery strictly increases investors' subjective welfare.

To analyze naive investors' objective welfare, we note that naive investors' portfolio in the economy in Section 3 can be decomposed into one unit in assets 1 and 2 , and a position $x_{t}$ (for $t=0,1$ ) in the long-short strategy (long asset 1 and short asset 2). It is easy to show that naive investors' objective welfare $E\left[\log \left(W_{2}\right)\right]$ is concave in $x_{0}$ and $x_{1}$. In the pre-discovery case, $x_{0}=x_{1}=0$. In the post-discovery case, however, $x_{t}$ is "further away" from the optimum point for maximizing $E\left[\log \left(W_{2}\right)\right]$. For example, an naive investor's choice is $x_{0}<0$ although $\partial E\left[\log \left(W_{2}\right)\right] /\left.\partial x_{0}\right|_{x_{0}=0}>0$. Therefore, an naive investor's objective welfare is lower in the postdiscovery case. 
Table 1: Baseline Parameterizations

\begin{tabular}{lrrrrrrrrr}
\hline Parameter & $W_{0}^{a}$ & $k$ & $\rho$ & $\mu$ & $\sigma$ & $p$ & $\mu_{e}$ & $\sigma_{e}$ & $p_{e}$ \\
Value & 1 & 1 & 1 & 1.2 & 0.6 & 0.5 & 1.4 & 0.5 & 0.5 \\
\hline
\end{tabular}

This table reports the baseline parameter values in our numerical analysis.

Table 2: Anomalies and Their Citation Counts

\begin{tabular}{llrrr}
\hline Anomaly & Paper & Pub. Date & Data Start & Citation \\
\hline Momentum & Jegadeesh and Titman (1993) & Mar 1993 & Jan 1927 & 6089 \\
Size & Banz (1981) & Sep 1981 & Jan 1927 & 4608 \\
Value & Jun 1983 & Jan 1927 & 1317 \\
Size/Value & Fama and French (1992) & Jun 1992 & Jan 1927 & 11821 \\
\hline O-score & Mar 1980 & Jul 1961 & 3542 \\
Net stock issue & Ritter (1991) & Mar 1991 & Jul 1964 & 3374 \\
Total accruals & Sloan (1996) & Jul 1996 & Jul 1964 & 2894 \\
Investment to assets & Titman et. al. (2004) & Dec 2004 & Jul 1964 & 551 \\
Net operating assets & Hirshleifer et. al. (2004) & Dec 2004 & Jul 1964 & 312 \\
Composite equity issue & Daniel and Titman (2006) & Aug 2006 & Jul 1965 & 535 \\
Return on assets & Fama and French (2006) & Dec 2006 & Jan 1972 & 228 \\
Asset growth & Cooper et. al. (2008) & Aug 2008 & Jul 1964 & 409 \\
Financial distress & Campbell, et. al. (2008) & Dec 2008 & Jan 1976 & 727 \\
Gross profit to assets & Novy-Marx (2013) & Apr 2013 & Jul 1964 & 91 \\
\hline
\end{tabular}

This table lists anomalies and the studies that discover or popularize them. The third column reports the publication time of the studies. For size, value and momentum, we obtain the decile portfolio monthly returns from Kenneth French's website. For all the other anomalies, we follow the original studies to sort portfolios and compute their returns. The starting time of the return for each anomaly is reported in the forth column, Data Start. All the portfolio return series end in December 2012. The last column reports the number of citations for each study according to Google Scholar on Oct 16, 2014. 
Table 3: Summary Statistics

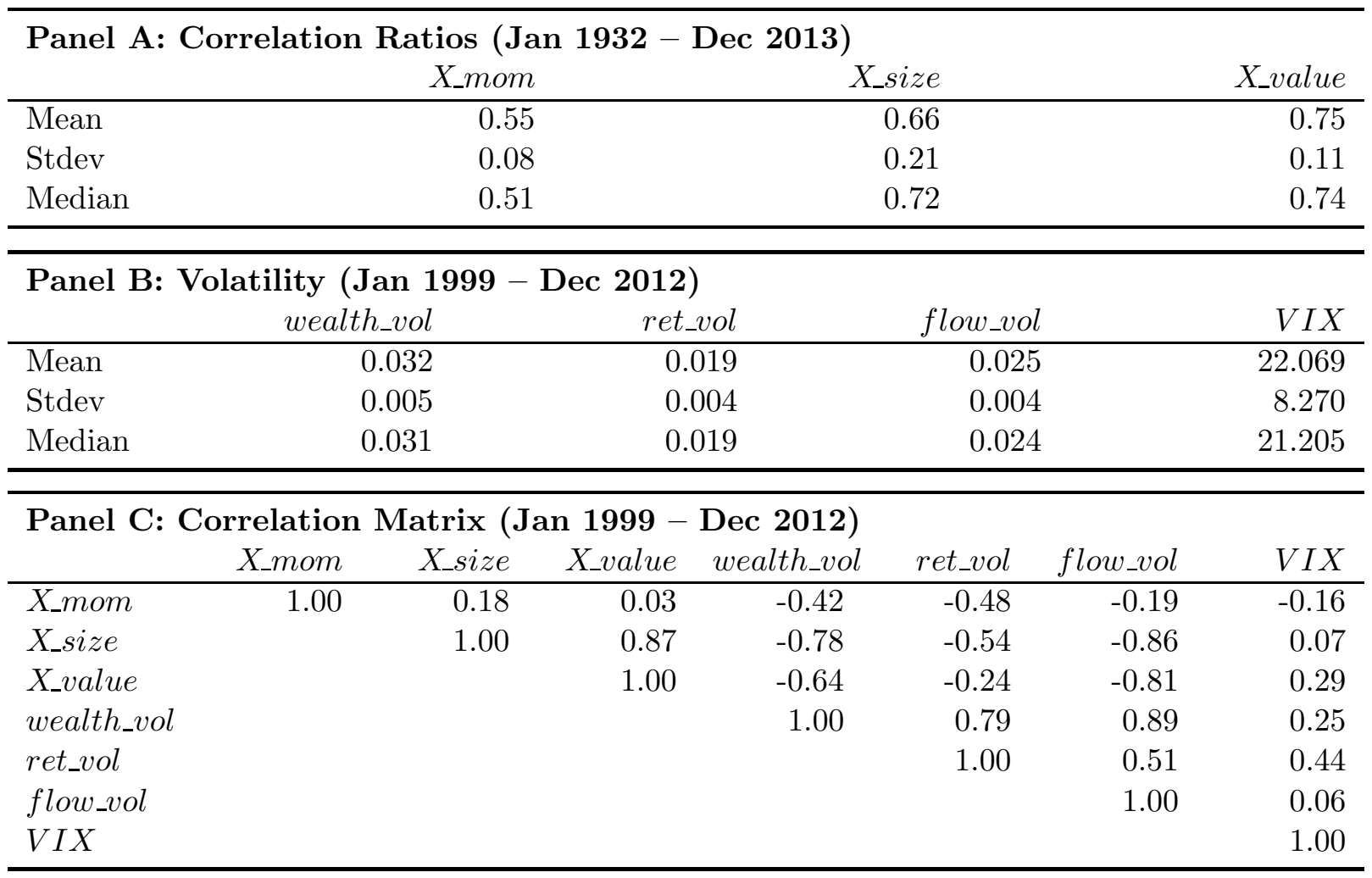

Panel A reports the mean, standard deviation, and median of the correlation ratio $X_{t}$, defined in (16). X_mom, $X_{-}$size, and $X_{-}$value are for momentum, size and value anomalies, respectively. Panel B reports the mean, standard deviation, and median of wealth_vol $_{t}$, ret_vol $_{t}$, flow_vol $_{t}$ and $V I X$. wealth_vol ${ }_{t}$ is the standard deviation of the monthly percentage changes in the total assets under management by all hedge funds. ret_vol $t$ is the standard deviation of the monthly value weighted returns among all hedge funds reported in TASS. flow_vol $l_{t}$ is the standard deviation of the monthly flows, in percentage, to all hedge funds in TASS. These three variables are estimated based on a rolling window of the prior 60-month data. We only include funds that have been reporting to TASS for more than or equal to 2 months. VIX is the monthly series of the implied volatility of S\&P 500 index options on the Chicago Board Options Exchange. 
Table 4: Pre- and Post-discovery Correlations (Jan 1932-Dec 2012)

\begin{tabular}{lrrrrr}
\hline & $\begin{array}{r}\text { Momentum } \\
(\text { Mar 1993) }\end{array}$ & $\begin{array}{r}\text { Size } \\
(\text { Sep 1981) }\end{array}$ & $\begin{array}{r}\text { Size } \\
\text { (Jun 1992) }\end{array}$ & $\begin{array}{r}\text { Value } \\
\text { (Jun 1983) }\end{array}$ & $\begin{array}{r}\text { Value } \\
\text { (Jun 1992) }\end{array}$ \\
\hline Discovery & $-0.13^{* * *}$ & -0.07 & $-0.14^{*}$ & $-0.09^{*}$ & $-0.13^{* *}$ \\
& $(-3.97)$ & $(-1.15)$ & $(-1.78)$ & $(-1.75)$ & $(-1.96)$ \\
\hline \#obs & 972 & 972 & 972 & 972 & 972 \\
adj_R $R^{2}$ & 0.387 & 0.075 & 0.236 & 0.126 & 0.194 \\
\hline
\end{tabular}

This table reports, for each anomaly, the results from regressions of the correlation ratio $X_{t}$, defined in (16), on the dummy variable Discovery, which is 0 before the discovery time and 1 afterwards. The discovery time is in the parenthesis at the top of each column. The $t$-statistics are reported in the parenthesis under each coefficient estimate, and are based on the standard errors with Newey-West adjustment with 60 lags. $*, * *$, and $* * *$ indicate that the coefficients are statistically significant at the $10 \%, 5 \%$, and $1 \%$ level, respectively. 
Table 5: Correlations and Hedge Funds (Jan 1999-Dec 2012)

\begin{tabular}{|c|c|c|c|c|}
\hline \multicolumn{5}{|c|}{ Panel A: Momentum } \\
\hline wealth_vol & $\begin{array}{r}-6.78^{* * *} \\
(-2.23)\end{array}$ & & & \\
\hline ret_vol & & $\begin{array}{r}-11.16^{* *} \\
(-2.36)\end{array}$ & & $\begin{array}{c}-12.26^{*} \\
(-1.88)\end{array}$ \\
\hline flow_vol & & & $\begin{array}{r}-3.83 \\
(-0.70)\end{array}$ & $\begin{array}{r}1.76 \\
(0.30)\end{array}$ \\
\hline$V I X$ & $\begin{array}{r}-0.05 \\
(-0.54) \\
\end{array}$ & $\begin{array}{r}0.06 \\
(1.59) \\
\end{array}$ & $\begin{array}{r}-0.14 \\
(-0.98) \\
\end{array}$ & $\begin{array}{r}0.08 \\
(1.10) \\
\end{array}$ \\
\hline $\begin{array}{l}\# \text { of obs } \\
\text { adj__ } R^{2}\end{array}$ & $\begin{array}{r}168 \\
0.17\end{array}$ & $\begin{array}{r}168 \\
0.22\end{array}$ & $\begin{array}{r}168 \\
0.05\end{array}$ & $\begin{array}{r}168 \\
0.22\end{array}$ \\
\hline \multicolumn{5}{|c|}{ Panel B: Size } \\
\hline wealth_vol & $\begin{array}{r}-37.31^{* * *} \\
(-6.25)\end{array}$ & & & \\
\hline ret_vol & & $\begin{array}{r}-41.29^{* * *} \\
(-4.31)\end{array}$ & & $\begin{array}{r}-15.55^{* *} \\
(-2.18)\end{array}$ \\
\hline flow_vol & & & $\begin{array}{r}-48.33^{* * *} \\
(-12.52)\end{array}$ & $\begin{array}{r}-41.24^{* * *} \\
(-8.95)\end{array}$ \\
\hline$V I X$ & $\begin{array}{r}0.71^{* * *} \\
(6.37) \\
\end{array}$ & $\begin{array}{r}0.95^{* * *} \\
(5.03) \\
\end{array}$ & $\begin{array}{l}0.31^{* *} \\
(2.52) \\
\end{array}$ & $\begin{array}{r}0.58^{* * *} \\
(5.02) \\
\end{array}$ \\
\hline $\begin{array}{l}\# \text { of obs } \\
\text { adj_- } R^{2}\end{array}$ & $\begin{array}{c}168 \\
0.67\end{array}$ & $\begin{array}{c}168 \\
0.40\end{array}$ & $\begin{array}{l}168 \\
0.75\end{array}$ & $\begin{array}{r}168 \\
0.79\end{array}$ \\
\hline \multicolumn{5}{|c|}{ Panel C: Value } \\
\hline wealth_vol & $\begin{array}{r}-17.62^{* * *} \\
(-6.74)\end{array}$ & & & \\
\hline ret_vol & & $\begin{array}{r}-13.88^{* * *} \\
(-3.98)\end{array}$ & & $\begin{array}{r}1.83 \\
(1.23)\end{array}$ \\
\hline flow_vol & & & $\begin{array}{r}-24.32^{* * *} \\
(-22.08)\end{array}$ & $\begin{array}{r}-25.16^{* * *} \\
(-20.49)\end{array}$ \\
\hline$V I X$ & $\begin{array}{r}0.63^{* * *} \\
(7.27)\end{array}$ & $\begin{array}{r}0.64^{* * *} \\
(5.89)\end{array}$ & $\begin{array}{c}0.44^{* *} \\
(6.99)\end{array}$ & $\begin{array}{r}0.41^{\text {*** }} \\
(6.87)\end{array}$ \\
\hline \# of obs & 168 & 168 & 168 & 168 \\
\hline $\operatorname{adj} R^{2}$ & 0.62 & 0.23 & 0.76 & 0.76 \\
\hline
\end{tabular}

This table reports, for each anomaly, the results of contemporaneous regressions of the correlation ratio $X_{t}$, defined in (16), on wealth_vol, ret_vol $_{t}, f_{\text {fow_vol }}$, and VIX . wealth_vol $l_{t}$ is the standard deviation of the monthly percentage changes in the assets under management by all hedge funds during the prior 60 months, ret_vol, the standard deviation of the monthly hedge fund index returns during the prior 60 months, flow_vol $l_{t}$, the standard deviation of the monthly flows, in percentage, to all hedge funds during the prior 60 months, and $V I X_{t}$, the implied volatility of S\&P 500 index options in the current month. Hedge funds data are from the TASS database. We only include funds that have been reporting to the database for more than or equal to 2 months. The $t$-statistics are reported in the parenthesis under each coefficient estimate, and are based on the standard errors with the Newey-West adjustment with 60 lags. $*, * *$, and $* * *$ indicate that the coefficients are statistically significant at the $10 \%, 5 \%$, and $1 \%$ level, respectively. 
Table 6: Pre- and Post-discovery Correlations in Panel Data (Jan 1932-Dec 2012)

\begin{tabular}{lc}
\hline Discovery & $\begin{array}{c}-0.052^{*} \\
(-1.91)\end{array}$ \\
\hline \# of obs & 7,419 \\
\# of anomaly & 12 \\
adj_ $R^{2}$ & 0.052 \\
\hline
\end{tabular}

This table reports the results from a panel regression of the correlation ratio $X_{t}$, defined in (16), on the dummy variable Discovery, which is 0 before the discovery time and 1 afterwards. The regression includes anomaly-fixed effects. T-statistics are reported in the parenthesis, and are based on standard errors that are clustered on anomaly. * indicates that the coefficient is statistically significant at the $10 \%$ level. 
Table 7: Correlations and Hedge Funds in Panel Data (Jan 1999-Dec 2012)

\begin{tabular}{|c|c|c|c|c|}
\hline \multicolumn{5}{|c|}{ Panel A: All sample } \\
\hline wealth_vol & $\begin{array}{r}-4.18 \\
(-1.00)\end{array}$ & & & \\
\hline ret_vol & & $\begin{array}{r}-3.38 \\
(-1.01)\end{array}$ & & $\begin{array}{r}-1.76 \\
(-0.96)\end{array}$ \\
\hline flow_vol & & & $\begin{array}{r}-4.85 \\
(-0.90)\end{array}$ & $\begin{array}{r}-3.97 \\
(-0.82)\end{array}$ \\
\hline$V I X$ & $\begin{array}{c}0.035 \\
(0.35)\end{array}$ & $\begin{array}{r}0.032 \\
(0.34)\end{array}$ & $\begin{array}{l}-0.012 \\
(-0.17)\end{array}$ & $\begin{array}{r}0.016 \\
(0.20)\end{array}$ \\
\hline \# of obs & 2,016 & 2,016 & 2,016 & 2,016 \\
\hline \# of anomaly & 12 & 12 & 12 & 12 \\
\hline $\operatorname{adj} \_R^{2}$ & 0.038 & 0.020 & 0.034 & 0.038 \\
\hline \multicolumn{5}{|c|}{ Panel B: Post-discovery sample } \\
\hline wealth_vol & $\begin{array}{r}-11.75^{* *} \\
(-2.21)\end{array}$ & & & \\
\hline ret_vol & & $\begin{array}{c}-7.51^{* *} \\
(-2.30)\end{array}$ & & $\begin{array}{r}-4.88^{* *} \\
(-2.42)\end{array}$ \\
\hline flow_vol & & & $\begin{array}{r}-13.16^{*} \\
(-1.94)\end{array}$ & $\begin{array}{r}-11.62^{*} \\
(-1.83)\end{array}$ \\
\hline$V I X$ & $\begin{array}{r}0.16 \\
(1.36) \\
\end{array}$ & $\begin{array}{r}0.11 \\
(1.13) \\
\end{array}$ & $\begin{array}{r}0.05 \\
(0.57) \\
\end{array}$ & $\begin{array}{r}0.11 \\
(1.17) \\
\end{array}$ \\
\hline \# of obs & 1454 & 1454 & 1454 & 1454 \\
\hline \# of anomaly & 12 & 12 & 12 & 12 \\
\hline $\operatorname{adj} \_R^{2}$ & 0.219 & 0.090 & 0.197 & 0.232 \\
\hline
\end{tabular}

This table reports the results of panel regressions of the correlation ratio $X_{t}$, defined in (16), on wealth_vol, ret_vol $_{t}, f_{\text {fow_vol }}$, and $V I X_{t}$, with anomaly-fixed effects. The regression in Panel A includes all the data during Jan 1999-Dec 2012. The regression in Panel B excludes the prediscovery data for each anomaly. wealth_vol $t_{t}$ is the standard deviation of the monthly percentage changes in the assets under management by all hedge funds during the prior 60 months, ret_vol ${ }_{t}$, the standard deviation of the monthly hedge fund index returns during the prior 60 months, flow_vol, the standard deviation of the monthly flows, in percentage, to all hedge funds during the prior 60 months, and $V I X_{t}$, the implied volatility of S\&P 500 index options in the current month. Hedge funds data are from the TASS database. We only include funds that have been reporting to the database for more than or equal to 2 months. T-statistics are reported in the parenthesis, and are based on standard errors that are clustered on anomaly. $*, * *$, and $* * *$ indicate that the coefficients are statistically significant at the $10 \%, 5 \%$, and $1 \%$ level, respectively. 
Table 8: Average Correlation and Hedge Funds (Jan 1999-Dec 2012)

\begin{tabular}{|c|c|c|c|c|}
\hline \multicolumn{5}{|c|}{ Panel A: All sample } \\
\hline wealth_vol & $\begin{array}{r}-4.18^{* * *} \\
(-4.81)\end{array}$ & & & \\
\hline ret_vol & & $\begin{array}{r}-3.38^{* *} \\
(-2.59)\end{array}$ & & $\begin{array}{r}-1.76^{* *} \\
(-2.59)\end{array}$ \\
\hline flow_vol & & & $\begin{array}{r}-4.85^{* * *} \\
(-5.35)\end{array}$ & $\begin{array}{r}-3.97^{* * *} \\
(-4.25)\end{array}$ \\
\hline$V I X$ & $\begin{array}{r}0.035 \\
(0.75)\end{array}$ & $\begin{array}{r}0.033 \\
(0.90)\end{array}$ & $\begin{array}{l}-0.012 \\
(-0.21)\end{array}$ & $\begin{array}{r}0.016 \\
(0.39)\end{array}$ \\
\hline \# of obs & 168 & 168 & 168 & 168 \\
\hline \# of anomaly & 12 & 12 & 12 & 12 \\
\hline $\operatorname{adj} \_R^{2}$ & 0.419 & 0.220 & 0.374 & 0.420 \\
\hline \multicolumn{5}{|c|}{ Panel B: Post-discovery sample } \\
\hline wealth_vol & $\begin{array}{r}-15.88^{* * *} \\
(-16.24)\end{array}$ & & & \\
\hline ret_vol & & $\begin{array}{r}-13.63^{* * *} \\
(-3.57)\end{array}$ & & $\begin{array}{r}-7.70^{* * *} \\
(-6.42)\end{array}$ \\
\hline flow_vol & & & $\begin{array}{r}-18.33^{* * *} \\
(-8.10)\end{array}$ & $\begin{array}{r}-14.47^{* * *} \\
(-20.24)\end{array}$ \\
\hline$V I X$ & $\begin{array}{r}0.20^{* * *} \\
(4.39)\end{array}$ & $\begin{array}{r}0.20^{* * *} \\
(3.04)\end{array}$ & $\begin{array}{r}0.015 \\
(0.17) \\
\end{array}$ & $\begin{array}{r}0.14^{* * *} \\
(4.55)\end{array}$ \\
\hline \# of obs & 168 & 168 & 168 & 168 \\
\hline \# of anomaly & 12 & 12 & 12 & 12 \\
\hline $\operatorname{adj} R^{2}$ & 0.832 & 0.493 & 0.734 & 0.861 \\
\hline
\end{tabular}

This table reports the results of a contemporaneous time-series regression of the average correlation ratio $X_{t}$, defined in (16), across anomalies, on wealth_vol, ret_vol, flow_vol , $_{\text {, }}$ and VIX $X_{t}$. The regression in Panel A includes all the data during Jan 1999-Dec 2012. The regression in Panel B excludes the pre-discovery data for each anomaly. wealth_vol $l_{t}$ is the standard deviation of the monthly percentage changes in the assets under management by all hedge funds during the

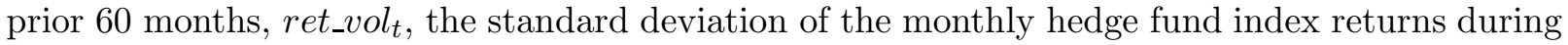
the prior 60 months, flow_vol, , the standard deviation of the monthly flows, in percentage, to all hedge funds during the prior 60 months, and VIX options in the current month. Hedge funds data are from the TASS database. We only include funds that have been reporting to the database for more than or equal to 2 months. T-statistics are reported in the parenthesis, and are based on the Newey-West adjustment with 60 lags. *,**, and $* * *$ indicate that the coefficients are statistically significant at the $10 \%, 5 \%$, and $1 \%$ level, respectively. 
Figure 1: Correlations
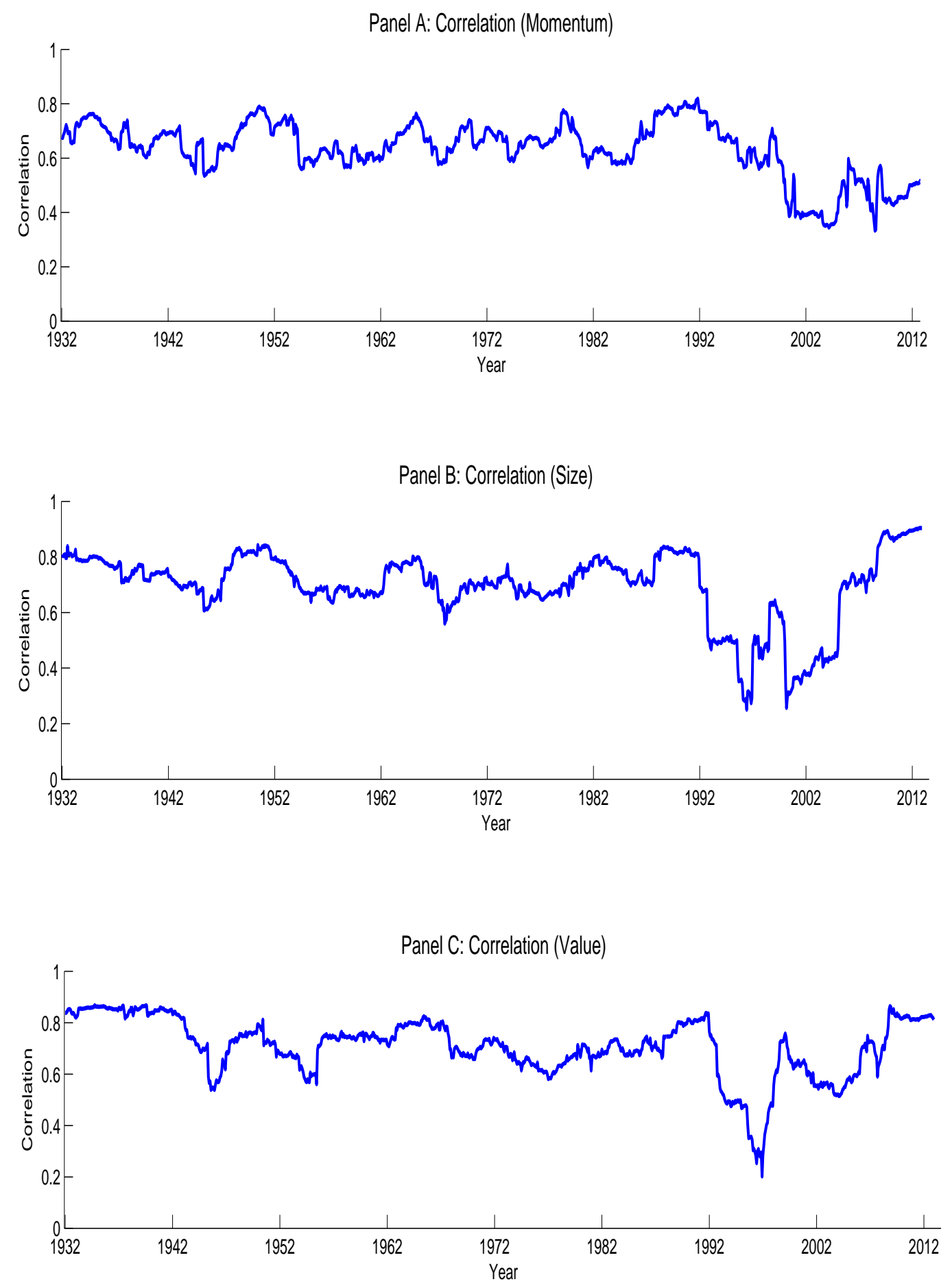

Panels $\mathrm{A}-\mathrm{C}$ plot the correlation coefficient between the excess returns of deciles 1 and 10 for momentum, size and value, respectively. The correlation coefficients are estimated based on a 5 -year rolling window of monthly data. 
Figure 2: Anomaly Return
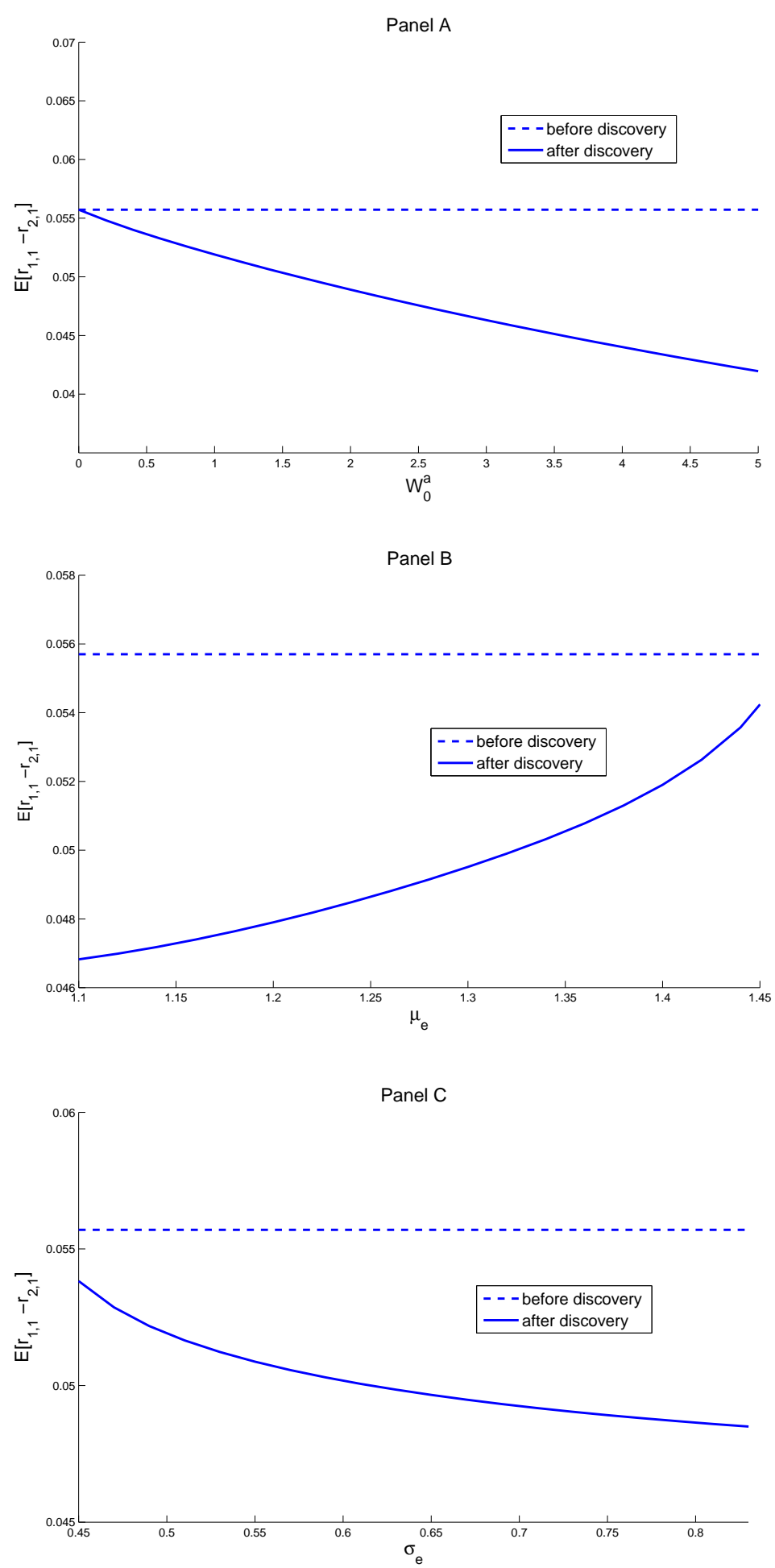

Panels A-C plot the expected anomaly return, $E\left[r_{1,1}-r_{2,1}\right]$, on arbitrageurs' initial wealth $W_{0}^{a}$, asset $e$ 's expected return $\mu_{e}$ and volatility $\sigma_{e}$, respectively. The parameter values are given by Table 1. 
Figure 3: Correlation Among Anomaly Returns
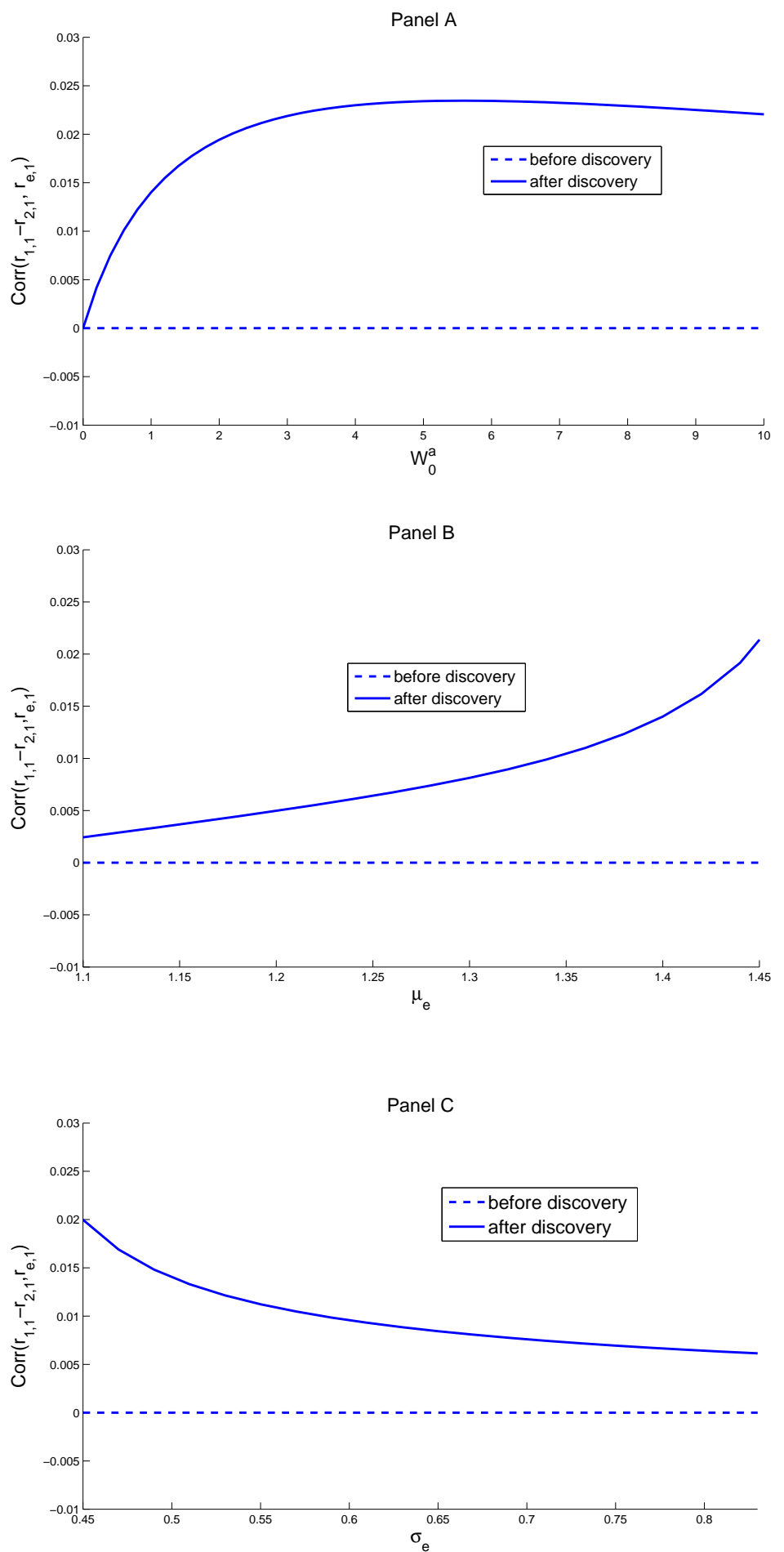

Panels A-C plot the correlation coefficient between the anomaly return and asset $e$ 's return, $\operatorname{Corr}\left(r_{1,1}-r_{2,1}, r_{e, 1}\right)$, on arbitrageurs' initial wealth $W_{0}^{a}$, asset $e$ 's expected return $\mu_{e}$, and its volatility $\sigma_{e}$, respectively. The parameter values are given by Table 1 . 
Figure 4: Correlation Between Assets 1 and 2
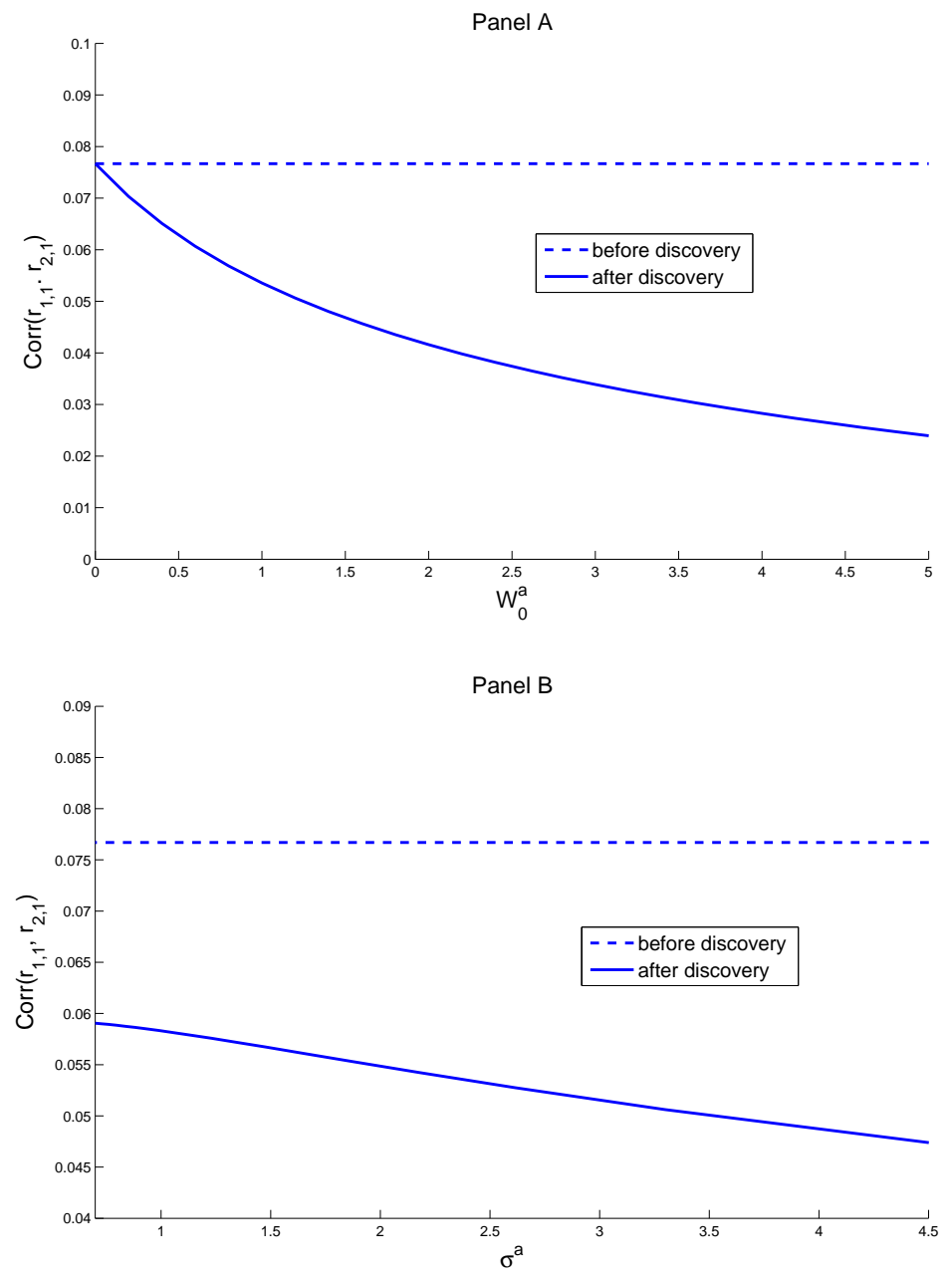

Panels A and B plot the correlation coefficient between assets 1 and $2, \operatorname{Corr}\left(r_{1,1}, r_{2,1}\right)$, on arbitrageurs' initial wealth $W_{0}^{a}$, and their wealth volatility $\sigma^{a}$, respectively. The parameter values are given by Table 1 . 


\section{Figure 5: Comparison: Asset Prices}
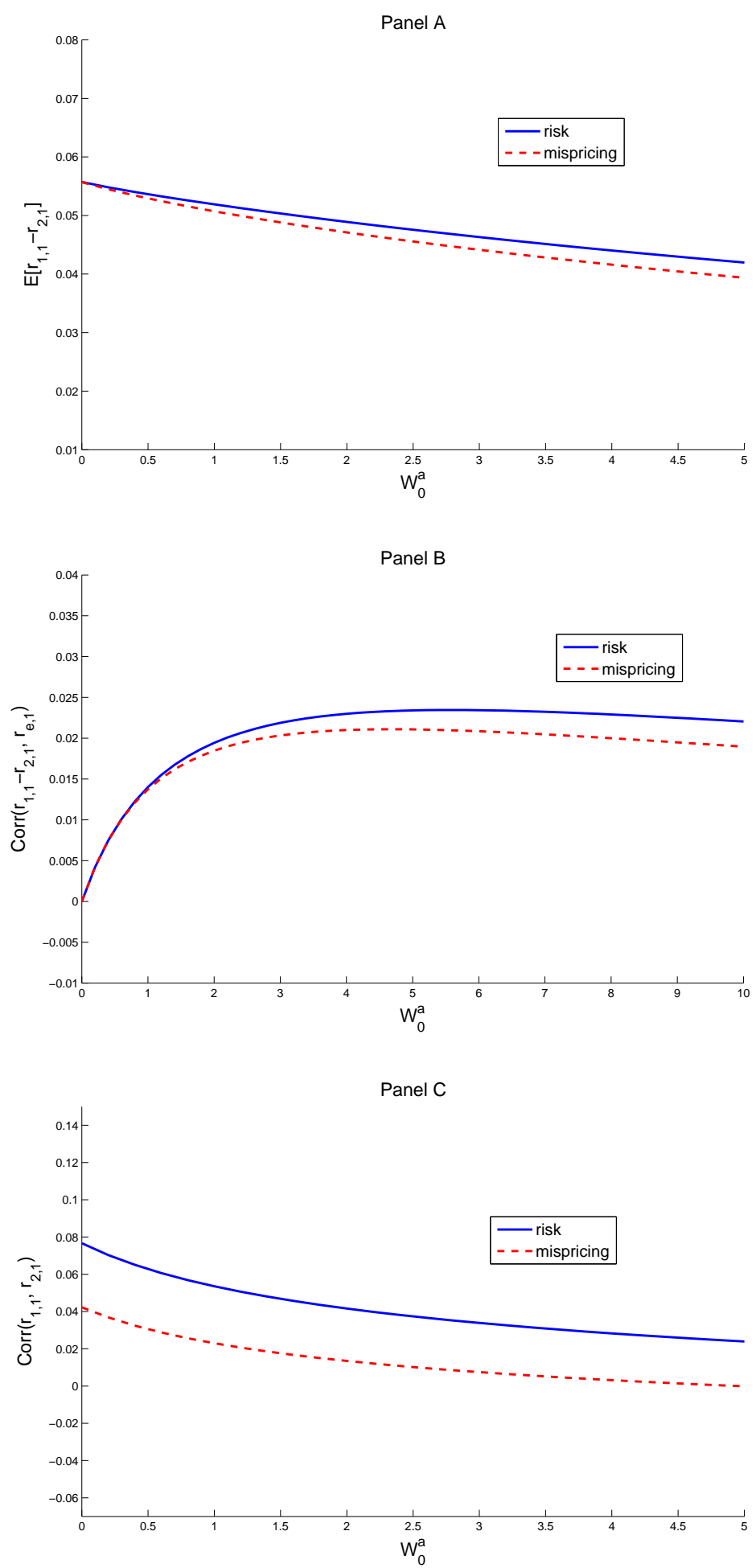

Panels A-C plot the expected anomaly return, $E\left[r_{1,1}-r_{2,1}\right]$, its correlation with asset $e$ 's return, $\operatorname{Corr}\left(r_{1,1}-r_{2,1}, r_{e, 1}\right)$, and the correlation between assets 1 and $2, \operatorname{Corr}\left(r_{1,1}, r_{2,1}\right)$, on arbitrageurs' initial wealth $W_{0}^{a}$, respectively. The solid line is for the risk-based case, and the dashed line the mispricing-based case. Parameter values: $b=0.055$, and other parameter values are given by Table 1. 